\title{
Conocimiento y percepción de la avifauna en niños de dos comunidades en la selva Lacandona, Chiapas, México: hacia una conservación biocultural Knowledge and perception of the avifauna among children of two communities in the Lacandona rainforest, Chiapas, Mexico: toward a biocultural conservation
}

Martha del C. Rodríguez-Ramírez ${ }^{1}$, E. Miriam Aldasoro-Maya², Carla B. Zamora-Lomelí ${ }^{3}$ y Juan J. Velasco-Orozco ${ }^{4}$

Palabras Clave: conocimiento local; valoración; niños; aves; etnoornitología

Recepción: 13-03-17 / Aceptación: 15-09-17

\section{Resumen}

Este artículo documenta y analiza el Conocimiento Tradicional (CT), usos y percepciones de los niños sobre las aves en las comunidades Reforma Agraria (RA) y Frontera Corozal (FC) que se encuentran en la zona Lacandona en Chiapas, México. Ambas pertenecen a la zona de influencia de la Reserva de la Biósfera Montes Azules (REBIMA) y la segunda también del Monumento Natural Yaxchilán (MNY). Se realizaron actividades participativas en las escuelas de educación básica que consistían en cuestionarios, entrevistas, sociodramas, elaboración de dibujos y de historias sobre las aves, entre otras. Los niños reconocen 42 especies de aves (en RA) y 31 especies en cada una de las dos escuelas de FC, e identifican su uso como mascotas, ornamentales (las plumas), comestibles, agoreras y en algunos casos medicinales. Su conocimiento se basa en su cercanía con la selva y en la observación recurrente de su entorno. La percepción que tienen de la avifauna es positiva. Sienten una gran atracción y aprecio debido a sus colores, cantos y diversidad. Actualmente las instituciones de gobierno aprovechan escasamente las oportunidades alrededor de este conocimiento y es necesario que se considere para apoyar la conservación de estos organismos y la de su entorno ecológico, incorporando cada vez más un enfoque biocultural e intercultural en sus actividades.

\footnotetext{
${ }^{1}$ Maestría en Ciencias en Recursos Naturales y Desarrollo Rural. El Colegio de la Frontera Sur, Campus Villahermosa. E-mail: ealdasoro@ecosur.mx

${ }^{2}$ Departamento de Agricultura, Sociedad y Ambiente, El Colegio de la Frontera Sur, Campus Villahermosa.

${ }^{3}$ Departamento de Agricultura, Sociedad y Ambiente, El Colegio de la Frontera Sur, Campus San Cristóbal de Las Casas.

${ }^{4}$ Facultad de Antropología. Universidad Autónoma del Estado de México.

(C) Universidad De La Salle Bajío (México)
} 


\begin{abstract}
This article documents and analyzes Traditional Knowledge (CT), uses and perceptions of birds by children in Reforma Agraria (RA) and Frontera Corozal (FC) communities located in the Lacandon area of Chiapas, Mexico. Both belong to the zone of influence of the Montes Azules Biosphere Reserve (REBIMA) and the second also to the Yaxchilán Natural Monument (MNY). Participatory activities were carried out in basic education schools consisting of questionnaires, interviews, sociodramas, elaboration of drawings and stories about birds, among others. The children recognize 42 species of birds (in RA) and 31 species in each of the two FC schools, and identify their use as pets, ornamental (feathers), edible, harbinger birds and in some cases medicinal. Their knowledge is based on their proximity to the jungle and the recurrent observation of their environment. Their perception of birdlife is positive. They feel a great attraction and appreciation because of their colors, songs and diversity. Currently, government institutions are making limited use of the opportunities around this knowledge that must be considered to support the conservation of these organisms and their ecological environment, increasingly incorporating a biocultural and intercultural approach in their activities.
\end{abstract}

Keywords: local knowledge; assessment; children; birds; ethnoornithology.

\title{
Introducción
}

México alberga aproximadamente dos terceras partes de la biodiversidad mundial, ocupando el cuarto lugar por su riqueza de especies. Además de esta elevada diversidad biológica, también cuenta con una gran riqueza cultural (Sarukhán, et al. 2009, 9), esto lo convierte en el cuarto país con mayor riqueza biocultural (Toledo, 2003, 70). La diversidad biocultural es un importante campo de investigación transdisciplinaria que surge en la última década y se enfoca en el estudio de los vínculos entre la diversidad lingüística, cultural y biológica como manifestaciones de la vida (Maffi 2005, 612, 613). De acuerdo con esta propuesta, resulta prioritario realizar actividades que propicien la vinculación entre las personas y el entorno ambiental, fomentando así la conservación de su identidad (Aldasoro y Maya, 2010, 149). Para el caso de México hay dos enfoques importantes en materia de conservación y sustentabilidad: el biocultural, que constituye una estrategia de las comunidades en los procesos de apropiación social de la naturaleza y sus opciones

№ 19, Vol. 9 (2), 2017. ISSN 2007 - 0705, pp.: 660 - 716 
de aprovechamiento (Toledo, 2003, 115; Boege, 2008, 39) y el intercultural como una aspiración al respeto, buscando eliminar las desigualdades que benefician a un grupo cultural o que están mediadas por el poder (Schmelkes, 2006, 122).

El objetivo general del presente estudio fue documentar, describir y analizar el Conocimiento Tradicional (CT) y la percepción que tienen los niños sobre las aves en dos comunidades pertenecientes a zonas de influencia de Área Natural Protegida (ANP). Las aves son uno de los grupos más carismáticos y llamativos por sus colores y cantos, además de que es relativamente fácil observarlas y siempre han tenido gran cercanía con el ser humano (NavarroSigüenza et al. 2014, 477).

Existe una estrecha correlación entre la diversidad de aves y la lingüística; de los 14 países con mayor diversidad de aves hay siete con mayor número de lenguas endémicas, esto relaciona al $40 \%$ de países con gran diversidad de aves y al $47 \%$ de todos los lenguajes del mundo (Toledo y Barrera, 2008, 63). La relación entre las culturas y las aves forma parte importante del patrimonio biocultural de nuestro país (Núñez-García et al. 2012, 15). Este patrimonio es un instrumento en los procesos de enseñanza-aprendizaje en la biología de la conservación para generar estrategias de desarrollo sostenible (Benites y Mamede, 2008, 264). Al explorar los intereses, conocimiento y percepciones de los niños se genera un referente sobre la experiencia de esta población, que es el grupo que a futuro tomará decisiones sobre el manejo de los recursos naturales y la conservación de la biodiversidad (Fernández et al. 2010, 36).

Los objetivos específicos fueron registrar las especies de aves que reconocen los niños de educación primaria y la percepción que tienen de ellas. Cabe mencionar que en la presente investigación nos referimos a niños y no a "niños y niñas" debido a que de acuerdo con la Real Academia Española "la mención explícita del femenino solo se justifica cuando la oposición de sexos es relevante en el contexto", lo cual no sucede en esta investigación (RAE, 2017). La investigación parte del reconocimiento de que ambas comunidades tienen un contexto histórico y cultural propio y que por lo tanto habrá variación en el conocimiento.

Para adquirir un conocimiento se lleva a cabo un proceso de selección y elaboración de una interpretación posterior a una experiencia percibida, se otorgan significados y se elaboran juicios sobre el ambiente que nos rodea. La percepción es entendida como un proceso con el que se reconoce, se interpreta y se da significado a los hechos. Las percepciones y valoraciones que se dan a los organismos varían de acuerdo a los contextos culturales, es decir, dependen de la cultura 
que incluye todos los "rasgos distintivos espirituales, materiales, intelectuales y afectivos que caracterizan a un grupo social" (UNESCO, 2002, 4) y que influyen en los criterios y las creencias de las personas (Venegas-Segura, 2013, 177).

Es indispensable documentar el conocimiento ya que éste se encuentra en un proceso de erosión dentro de las comunidades indígenas y locales. Su prevalencia es cuestionada a medida que se da un proceso de modernización, que aunado a los rápidos cambios socioeconómicos y culturales, produce una falta de transmisión intergeneracional a largo plazo (Zent, 2001, 207; Cristancho y Vining, 2009, 232-234). Se requiere que las prácticas de las comunidades se mantengan funcionales en la interacción con su entorno y que se conozcan los factores del cambio cultural. Las culturas con una tradición oral tienen mayor riesgo en comparación con las culturas que poseen idiomas escritos (Oviedo et al. 2007, 2). Si se toma en cuenta el aspecto cultural, se puede contribuir a la valoración de sistemas de conocimiento alternativo para que sean reconocidos como un legado (Dufour 2006, 1; Aldasoro y Maya 2010, 153) y de esta manera se avance hacia una mayor justicia cognitiva (de Sousa, 2009, 12).

Se decidió analizar el conocimiento sobre las aves en comunidades de Chiapas ya que la diversidad de este grupo de organismos es considerable, con 694 especies y 38 de probable ocurrencia lo que daría un total de 732 especies (CONABIO, 2013, 259). Esta diversidad, y la abundancia y distribución de especies se deben a las condiciones biogeográficas del estado. En la zona de la Reserva de la Biósfera Montes Azules (REBIMA), en particular, hay una gran variedad de especies de aves y la mayoría responden al grado de conservación, como también a la fragmentación y transformación del hábitat (Ramírez-Albores 2006, 11), dichas transformaciones pueden ser causadas por actividades humanas de una gran variedad de culturas que propician un cambio en el uso de suelo.

Las aves son un recurso natural usado como fuente de alimento, de importancia ornamental, con fines religiosos y como mascotas (Jiménez-Díaz et al. 2014, 83). Aunado a la riqueza cultural surge una asociación con la avifauna que crea una apropiación social que se traduce en una cosmovisión y en prácticas productivas (Núñez-García et al. 2012, 16).

La investigación se llevó a cabo en la selva lacandona que se encuentra ubicada en el extremo oriental del estado de Chiapas. Es considerada una región prioritaria para la conservación de la biodiversidad (Carabias-Lillo et al. 2000,12). Ha estado sometida a presión antropogénica debida al cambio de uso de suelo para la agricultura y ganadería por el poblamiento de la selva a 
partir de la década de los setenta, lo que ha causado notables pérdidas de la vegetación original y ha generado gran deterioro ambiental (Carabias et al. 2006, 7).

Para conservar la biodiversidad se han designado áreas a cargo de la Comisión Nacional de Áreas Naturales Protegidas (CONANP). En la zona lacandona se localizan ocho ANP, siendo la de mayor tamaño la REBIMA (Carabias-Lillo et al. 2000, 13). La gobernanza de las ANP en esta zona implica retos sociopolíticos para su gestión y manejo sustentable ya que suelen existir varias problemáticas, por ejemplo las territoriales (Legorreta, 2014, 13).

Ambas localidades de estudio pertenecen a la zona de influencia de la REBIMA y una de ellas además, al Monumento Natural Yaxchilán (MNY). Resulta imprescindible documentar el conocimiento en estas comunidades ya que sus habitantes son los principales actores en el manejo y conservación de la diversidad biocultural, y en general los factores culturales no son considerados en planes de manejo y desarrollo. Se desconocen los impactos de las actividades de manejo en el conocimiento de los habitantes (Oviedo et al. 2007, 4) y menos aún en el de los niños.

La etnoornitología, enfoque utilizado en este estudio, incluye el estudio de las aves y las representaciones a través del arte, patrones de uso, las creencias sobre ellas como portadoras de mensajes y las interacciones que tiene el ser humano con este grupo de organismos en la cotidianeidad, por lo tanto, se refiere a las relaciones de una manera amplia entre las aves, los seres humanos y los demás seres vivos y no vivos o espirituales (Tidemann, 2010, 5). Por medio de los estudios etnoornitológicos se pretende acercar a la academia con los saberes comunitarios. Esta confluencia de disciplinas puede contribuir por un lado a la toma de acciones sobre la conservación, la gestión y protección de la avifauna, y por otro al reconocimiento de los sistemas de conocimiento tradicional (Bonta, 2010, 21).

Es relevante mencionar que ya se han realizado esfuerzos en este sentido, por iniciativa propia desde la población local. Un ejemplo es el trabajo de Alcántara-Salinas y colaboradores $(2015,1)$ que han estudiado la diversidad de aves y su relación con la conservación por parte de comunidades en Oaxaca, registrando nombres zapotecos y creencias culturales así como prácticas relativas a las aves y actitudes de los pobladores. Este trabajo aporta evidencia de como el CT presente en las comunidades indígenas puede coadyuvar en la conservación de la diversidad biológica. 


\section{Método}

Se seleccionaron dos comunidades para la investigación, Reforma Agraria perteneciente al municipio de Marqués de Comillas y Frontera Corozal del municipio de Ocosingo, Chiapas, México (Figura 1). Ambas son importantes para la conservación debido a que se encuentran en zona de influencia de ANP. La REBIMA tiene relevancia ecológica nacional e internacional, se le han invertido grandes recursos financieros y se le considera como muy amenazada. A lo largo de su gestión se han presentado varios conflictos sociales y enfrentamientos entre las comunidades y con las autoridades ambientales (Durand y Figueroa 2014, 109, 110). El ejido Reforma Agraria fue habitado a partir de 1974 por pobladores chinantecos procedentes de Oaxaca y de varias regiones de Chiapas (Cano, 2013, 48, 102). Se localiza al sur de la REBIMA, en el municipio Marqués de Comillas, en las coordenadas $16^{\circ} 54^{\prime} 21^{\prime \prime}$ Norte y $92^{\circ} 05^{\prime} 37^{\prime \prime}$ Oeste. Se ubica en el límite oriental de la subcuenca del río Lacantún (Plan de desarrollo municipal Marqués de Comillas 2011-2012, 103, 105). Consta de 2463 ha, con un área de asentamiento urbano de 45 ha (Cano, 2013, 133, 137). La vegetación corresponde mayormente a selva alta y mediana perennifolia y presenta un clima cálido a semicálido húmedo (Carabias-Lillo et al. 2000, 37). Su población se reporta de entre 111 y 145 habitantes (INEGI, 2010; Plan de Desarrollo Municipal 2011-2012, 63). La tierra se destina al cultivo de maíz, frijol, chile y a la ganadería, razones por las cuales se ha provocado un gran deterioro ambiental, sin embargo, aún hay fragmentos de selva bien conservada (Carabias et al. 2006, 7; Cano, 2013, 240).

Desde la fundación del ejido se han realizado asambleas para la toma de decisiones y se llevan a cabo actividades de conservación y aprovechamiento sustentable de los recursos. Como resultado en 1997 se fundó la Sociedad Cooperativa Ara Macao, S.C.L. de C.V., que opera el Centro Ecoturístico Las Guacamayas y que cuenta con 22 socios; esta iniciativa es conocida tanto a nivel nacional como internacional y cuenta con una buena herramienta de promoción por medio de internet (Cano, 2013, 279). 


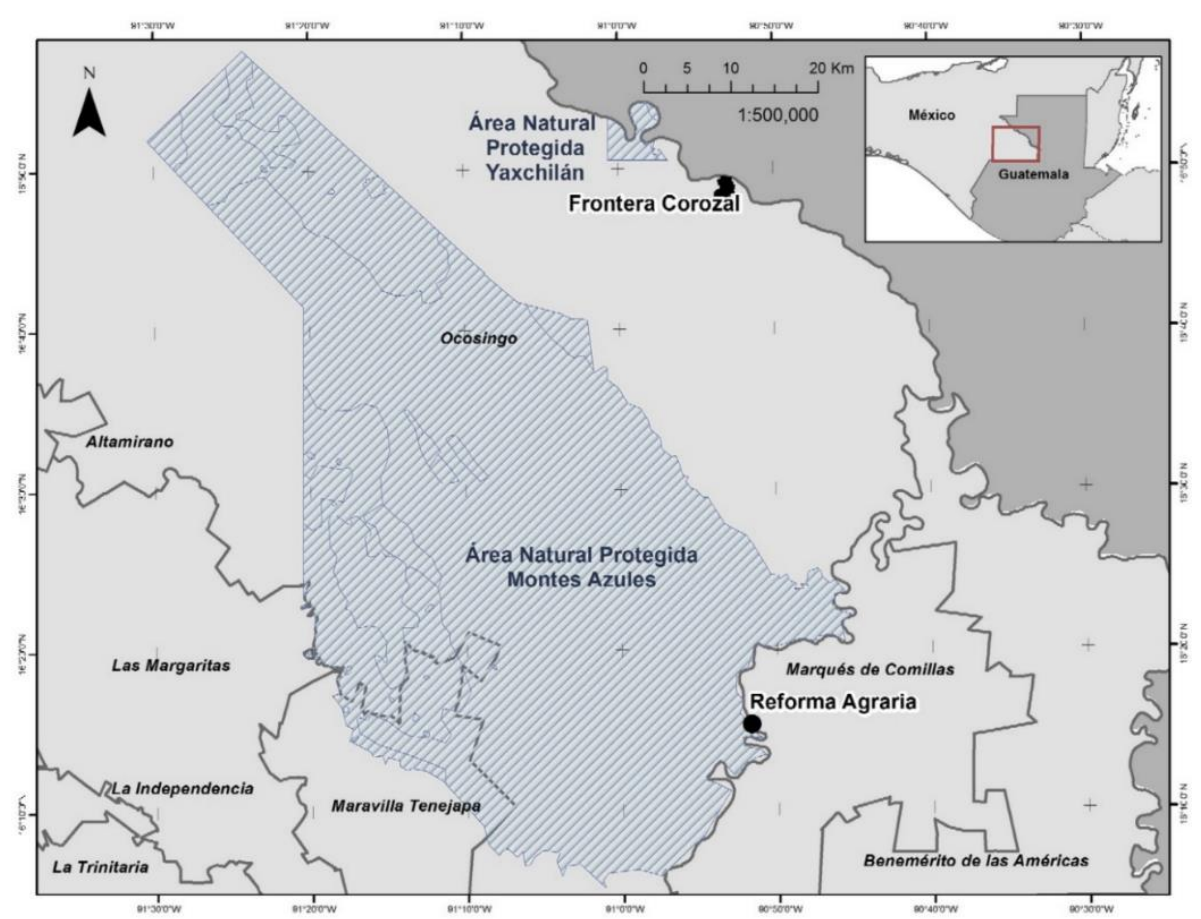

Figura 1. Comunidades de estudio (puntos) en el contexto regional. Los polígonos en azul corresponden a las ANP Montes Azules y Yaxchilán (elaborado con datos de la CONANP e INEGI en ArcGis10.3)

Algunos de los padres de los niños con los que se realizó la investigación trabajan en "las cabañas" como ellos llaman al centro ecoturístico, otros trabajan la tierra cerca de la comunidad o van a la comunidad Pico de Oro. La mayoría de las madres se dedican al hogar aunque algunas también trabajan en el centro ecoturístico. Los fundadores son chinantecos, sin embargo, sólo algunos adultos de la comunidad conservan la lengua indígena (Habitantes de la comunidad, com. pers.). Cuentan con una escuela primaria multigrado.

Frontera Corozal es una subcomunidad de la llamada Comunidad Zona Lacandona (Durand y Figueroa 2012, 4), fue reconocida en el año de 1979 y está conformada por 601 comuneros

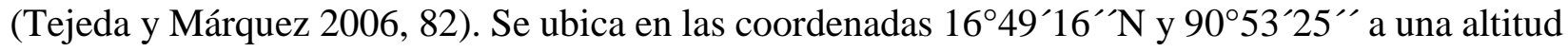
de 100 msnm. Su clima es semicálido húmedo. Su población se reporta entre 5184 y 6750 habitantes (INEGI, 2010; CEIEG, 2010) con un 77.48\% de habitantes hablantes de lengua Ch'ol. Gran parte de los comuneros en esta zona llegaron en la búsqueda de tierra fértil y son originarios de Tila, Tumbalá, Palenque y Sabanilla (Chiapas), con una cosmovisión que gira en torno al maíz (Tejeda y Márquez, 2006, 5). La comunidad cuenta con tres escuelas de educación primaria: dos 
bilingües con profesores hablantes de Ch'ol y una monolingüe donde los profesores imparten clases únicamente en español. La mayoría de los padres de familia en Frontera Corozal se dedican a la agricultura y al campo, otros son artesanos, hay algunos profesores, albañiles y taxistas, otros trabajan en el MNY; son pocas las madres que se dedican al campo, la mayoría se dedica al hogar. Los hijos varones por lo general son los que acompañan a los padres al monte, a la parcela o milpa y por lo tanto tienen mucho conocimiento sobre la naturaleza y las aves. Alrededor de un 3\% de la población adulta sale de la comunidad a trabajar toda la semana y dejan encargados a sus hijos con los abuelos (Profesores de la comunidad, com. pers.). La presente investigación fue previamente presentada y aprobada por las autoridades, directores y profesores de las escuelas primarias así como por padres y madres de familia en ambas comunidades. Durante el desarrollo del trabajo se utilizaron métodos cualitativos etnográficos, como la observación participante la cual garantiza la confiabilidad de los datos recogidos (Guber, 2001, 55). La información obtenida se registró en un diario de campo.

En términos de educación para un país multicultural como México, resulta necesario integrar el concepto de interculturalidad, entendido como una propuesta de diálogo e intercambio que articule las diferencias (López, 2001, 9); por lo tanto, las actividades se llevaron a cabo respetando la cultura y bajo un enfoque de diversidad biocultural, como lo proponen Aldasoro y Maya (2010, 148). Para la planeación de las actividades se consideraron los intereses de los niños con base en las visitas de prospección, entrevistas y cuestionarios piloto, estas se adecuaron a las edades y fueron las mismas en ambas comunidades, a excepción de las caminatas de observación con niños que únicamente se realizaron en RA. Al finalizar las sesiones se hizo una intervención puntual sobre la importancia de las aves y se presentó la nueva información de forma sencilla para que fuera integrada a su conocimiento previo.

La investigación se aborda bajo una perspectiva metodológica que contempla como unidades de análisis a los niños, los casos abordados se desarrollan en un contexto rural (Cuadro 1).

Cuadro 1. Unidades de análisis en Reforma Agraria, Municipio Marqués de Comillas, Chiapas y Frontera Corozal, Municipio de Ocosingo, Chiapas.

\begin{tabular}{llllll}
\hline \multicolumn{5}{c}{ Reforma Agraria } & \multicolumn{5}{c}{ Frontera Corozal } \\
\hline Escuela & Felipe & Escuela Leandro Valle (LV) & Escuela Jaime & Torres & Bodet \\
Carrillo & Puerto & monolingüe & (JTB) & & \\
(FCP) & & & bilingüe & & \\
Multigrado & & Grupos $6^{\circ} \mathrm{A} \mathrm{y} 6^{\circ} \mathrm{B}$ & Grupos $5^{\circ}$ y $6^{\circ}$ & \\
\hline
\end{tabular}

No 19, Vol. 9 (2), 2017. ISSN 2007 - 0705, pp.: 660 - 716 


\begin{tabular}{llll}
\hline Un grupo focal & Cada grupo dividido en dos & Cada grupo dividido en dos \\
& subgrupos focales & subgrupos focales \\
Seis a doce años & Once a trece años & Diez a catorce años
\end{tabular}

El objetivo de documentar los conocimientos es dejar un referente y ayudar a que esta información no se pierda, por lo tanto no se consideró pertinente realizar una comparación entre las comunidades ya que ambas poseen condiciones y antecedentes históricos distintos. Además durante el desarrollo de las actividades el número de niños que participaron fue muy distinto y esto podría generar una interpretación errónea que demeritara los saberes documentados. En ambas comunidades se obtuvieron listados libres de las aves con el nombre común que les dan los niños a los que se agregó el nombre científico, la categoría de riesgo según la Norma Oficial Mexicana 059 (NOM-059) y la Unión Internacional para la Conservación de la Naturaleza (UICN). Para el caso de Frontera Corozal se documentó además el nombre en Ch'ol y se anotó si la palabra hace alusión a algún aspecto del ave. Los nombres en lengua Ch’ol fueron analizados y revisados con apoyo de los profesores de $5^{\circ}$ y $6^{\circ}$ de la escuela bilingüe Jaime Torres Bodet y miembros hablantes de la cooperativa Siyaj Chan.

De manera individual se hicieron entrevistas semiestructuradas a los niños, elaboración de dibujos de su ave favorita obteniendo el número de frecuencias de las aves dibujadas, se documentaron historias o cuentos y se les pidió que elaboraran fichas con datos de su ave favorita. Además se realizaron actividades con grupos focales como sociodramas para identificar los problemas que enfrentan y provocan las aves, reconocimiento de cantos con grabaciones, talleres para generar compromisos y dinámicas para indagar sobre los usos y valoración que dan a las aves. Para obtener las descripciones generales sobre las aves se aplicaron cuestionarios estandarizados y con algunas preguntas abiertas. Se les explicó que el objetivo era saber cuáles aves de su comunidad conocían, lo que pensaban sobre ellas y cuál era su importancia.

En Reforma Agraria el listado de aves se complementó con observaciones de cinco recorridos realizados con los niños en los meses de marzo y agosto, a la orilla del río en el centro ecoturístico "Las Guacamayas" y en las calles de la comunidad. Dichas observaciones se hicieron con la ayuda de binoculares y el apoyo de guías de identificación de aves (Howell y Webb, 1995; Dunn y Alderfer, 1999; Kauffman, 2005; Van Perlo, 2006), además se tomaron fotografías y se puso atención a los cantos. En esta comunidad una vez aplicados los cuestionarios piloto se observaron deficiencias notables en el proceso de lectoescritura de los niños, por lo que al final de 
las actividades se combinaron un cuestionario y quince entrevistas semiestructuradas (siete niñas y ocho niños). En Frontera Corozal, para registrar los saberes sobre las aves, se trabajó con grupos focales y se generaron listados con base en la información obtenida en dinámicas dentro del salón de clases, a partir de la aplicación de tres cuestionarios en español y 27 entrevistas semiestructuradas (trece niños y catorce niñas). En esta comunidad no se realizaron recorridos de observación con los niños, sin embargo se obtuvieron otros listados de aves con ayuda de miembros de la Cooperativa Siyaj Chan (Anexo 1) resultado del monitoreo comunitario que realizan cada mes, en dos transectos de $1.6 \mathrm{~km}$ establecidos en la zona arqueológica de Yaxchilán y en el sendero Gargantas a $6 \mathrm{Km}$ del primer transecto. En ambas comunidades se realizó un análisis cualitativo de las entrevistas con ayuda del software QSR N6 Nudis't, formando categorías por medio de una codificación abierta (códigos en vivo). Posteriormente se obtuvieron categorías eje y se crearon códigos fusionados con una codificación selectiva que generó un mapa conceptual de las relaciones de los códigos y categorías con los que los niños relacionan y perciben a las aves.

Se llevó a cabo un análisis lexicográfico de los cuestionarios. Para ello, de cada respuesta se hizo una descripción creando categorías de análisis que se asocian a los principales contenidos, además de realizar un análisis de la percepción de cada categoría (en porcentajes) para el manejo de los datos y su interpretación. Se realizó también un conteo de las palabras y los adjetivos que mencionaron al preguntarles que piensan de las aves y se generaron nubes de palabras con ayuda de un generador en internet que representan las frecuencias (worditout.com). Se realizó además un proceso de triangulación de la información para contrastar y completar los datos obtenidos en todas las actividades realizadas.

Por último, se entrevistó al funcionario encargado de las actividades de monitoreo en la REBIMA de la CONANP, para conocer el enfoque y trabajo que la instancia gubernamental lleva a cabo con las comunidades y sobre los programas que implementan con niños en materia de conservación.

\section{Resultados}

\section{Conocimiento en Reforma Agraria}

\section{Especies identificadas y aspectos ecológicos}

En la escuela primaria Escuela Felipe Carrillo Puerto (FCP) reconocen 42 especies de aves de las cuales trece se encuentran en alguna categoría de riesgo según la NOM-059 (Cuadro 2). Se 
registraron otras especies que los niños no conocían o no mencionaron (Cuadro 3) que se incluyen como información complementaria al conocimiento de la avifauna en RA, dichas aves se observaron en los recorridos de observación en el Centro Ecoturístico Las Guacamayas, lugar al que los niños rara vez acuden. Las condiciones en el Centro constituyen una variación en la estructura de vegetación en comparación con el resto de la comunidad.

Cuadro 2. Listado de aves que conocen los niños en Reforma Agraria, Municipio Marqués de Comillas, Chiapas. Ordenados según la clasificación propuesta por la American Ornithologists' Union (AOU, 1998) y sus actualizaciones (AOU, 2015). La especie marcada con asterisco* es probable por las características de coloración que mencionaron, se anota SD ya que desconocen la información.

\begin{tabular}{|c|c|c|c|c|c|c|c|}
\hline & $\begin{array}{l}\text { Nombre } \\
\text { científico }\end{array}$ & $\begin{array}{l}\text { Nombre } \\
\text { que le dan } \\
\text { los niños }\end{array}$ & $\begin{array}{l}\text { NOM } \\
-059\end{array}$ & UICN & $\begin{array}{c}\text { Hora en } \\
\text { que se } \\
\text { observa }\end{array}$ & $\begin{array}{l}\text { Se } \\
\text { observa } \\
\text { todo el } \\
\text { año }\end{array}$ & $\begin{array}{l}\text { En dónde se } \\
\text { observa }\end{array}$ \\
\hline 1 & Tinamidae & perdiz & & & & no & río \\
\hline 2 & $\begin{array}{l}\text { Dendrocygna } \\
\text { autumnalis }\end{array}$ & pijiji & & $\mathrm{LC}$ & no & no & río \\
\hline 3 & $\begin{array}{l}\text { Penelope } \\
\text { purpurascens }\end{array}$ & cojolita & A & $\mathrm{LC}$ & $\begin{array}{l}\text { temprano- } \\
\text { tarde }\end{array}$ & sd & montaña \\
\hline 4 & Crax rubra & hocofaisán & A & VU & & no & montaña \\
\hline 5 & $\begin{array}{l}\text { Ardea } \\
\text { herodias }\end{array}$ & garza gris & & $\mathrm{LC}$ & $\begin{array}{l}\text { mañana- } \\
\text { tarde }\end{array}$ & sd & río \\
\hline 6 & Ardea alba & $\begin{array}{l}\text { garza } \\
\text { blanca }\end{array}$ & & $\mathrm{LC}$ & $\begin{array}{l}\text { mañana- } \\
\text { tarde }\end{array}$ & sí & río \\
\hline 7 & $\begin{array}{l}* \text { Egretta } \\
\text { caerulea }\end{array}$ & garza negra & & $\mathrm{LC}$ & $\begin{array}{l}\text { mañana- } \\
\text { tarde }\end{array}$ & sd & río \\
\hline 8 & $\begin{array}{l}\text { Cathartes } \\
\text { aura } \\
\text { Coragyps } \\
\text { atratus }\end{array}$ & zopilote & & $\mathrm{LC}$ & $\begin{array}{l}\text { mañana- } \\
\text { tarde }\end{array}$ & sí & comunidad \\
\hline 9 & $\begin{array}{l}\text { Sarcoramphu } \\
\text { s papa }\end{array}$ & zopilote rey & $\mathrm{P}$ & $\mathrm{LC}$ & & no & montaña \\
\hline 10 & Accipitridae & águila & & & día & sí & montaña y río \\
\hline 11 & $\begin{array}{l}\text { Rupornis } \\
\text { magnirostris }\end{array}$ & gavilán & & $\mathrm{LC}$ & sí & & $\begin{array}{l}\text { río y lo escuchan } \\
\text { en la comunidad }\end{array}$ \\
\hline 12 & $\begin{array}{l}\text { Pseudastur } \\
\text { albicollis }\end{array}$ & $\begin{array}{l}\text { gavilán } \\
\text { nevado }\end{array}$ & Pr & $\mathrm{LC}$ & sí & & montaña- \\
\hline 13 & $\begin{array}{l}\text { Harpia } \\
\text { harpyja }\end{array}$ & águila arpía & $\mathrm{P}$ & NT & $\begin{array}{l}\text { no la han } \\
\text { visto }\end{array}$ & $\begin{array}{l}\text { no la han } \\
\text { visto }\end{array}$ & montaña \\
\hline 14 & $\begin{array}{l}\text { Patagioenas } \\
\text { flavirostris }\end{array}$ & $\begin{array}{l}\text { paloma } \\
\text { morada }\end{array}$ & & $\mathrm{LC}$ & sí & sí & $\begin{array}{l}\text { comunidad- casa, } \\
\text { río y milpa }\end{array}$ \\
\hline 15 & $\begin{array}{l}\text { Columbina } \\
\text { talpacoti }\end{array}$ & tortolita & & $\mathrm{LC}$ & & sí & comunidad \\
\hline
\end{tabular}




\begin{tabular}{|c|c|c|c|c|c|c|c|}
\hline 16 & Piaya cayana & cuco & & $\mathrm{LC}$ & sí & & montaña \\
\hline 17 & $\begin{array}{l}\text { Crotophaga } \\
\text { sulcirostris }\end{array}$ & $\begin{array}{l}\text { vaquero } \\
\text { pijul o } \\
\text { garrapatero }\end{array}$ & & $\mathrm{LC}$ & & Sí & $\begin{array}{l}\text { comunidad- casa } \\
\text { y milpa }\end{array}$ \\
\hline 18 & Strigidae & búho & & & noche & no & comunidad \\
\hline 19 & $\begin{array}{l}\text { Florisuga } \\
\text { mellivora }\end{array}$ & colibrí & & $\mathrm{LC}$ & mañana & sí & casa y comunidad \\
\hline 20 & $\begin{array}{l}\text { Amazilia } \\
\text { tzacatl }\end{array}$ & colibrí & & $\mathrm{LC}$ & mañana & sí & comunidad y casa \\
\hline 21 & Trogonidae & trogón & & & & no & montaña \\
\hline 22 & $\begin{array}{l}\text { Momotus } \\
\text { lessonii }\end{array}$ & momoto & & $\mathrm{LC}$ & & & montaña \\
\hline 23 & Alcedinidae & $\begin{array}{l}\text { martín } \\
\text { pescador }\end{array}$ & & & sí & río & comunidad y río \\
\hline 24 & $\begin{array}{l}\text { Pteroglossus } \\
\text { torquatus }\end{array}$ & tucancillo & $\operatorname{Pr}$ & $\mathrm{LC}$ & mañana & sí & $\begin{array}{l}\text { comunidad- } \\
\text { escuela y río }\end{array}$ \\
\hline 25 & $\begin{array}{l}\text { Ramphastos } \\
\text { sulfuratus }\end{array}$ & tucán & A & $\mathrm{LC}$ & & sí & $\begin{array}{l}\text { comunidad- casa } \\
\text { y río }\end{array}$ \\
\hline 26 & $\begin{array}{l}\text { Melanerpes } \\
\text { aurifrons }\end{array}$ & chéjere & & $\mathrm{LC}$ & & sd & casa y río \\
\hline 27 & $\begin{array}{l}\text { Campephilus } \\
\text { guatemalensi } \\
s\end{array}$ & carpintero & $\operatorname{Pr}$ & $\mathrm{LC}$ & $\begin{array}{l}\text { mañana- } \\
\text { tarde }\end{array}$ & sí & $\begin{array}{l}\text { comunidad- casa } \\
\text { y río }\end{array}$ \\
\hline 28 & $\begin{array}{l}\text { Herpetothere } \\
\text { s cachinnans }\end{array}$ & $\begin{array}{l}\text { halcón } \\
\text { guaco }\end{array}$ & & $\mathrm{LC}$ & todo el día & no & comunidad \\
\hline 29 & $\begin{array}{l}\text { Micrastur } \\
\text { semitorquatu } \\
\text { s }\end{array}$ & guaquillo & $\operatorname{Pr}$ & $\mathrm{LC}$ & & & río \\
\hline 30 & $\begin{array}{l}\text { Eupsittula } \\
\text { canicularis y } \\
\text { Eupsittula } \\
\text { nana }\end{array}$ & perico & $\operatorname{Pr}$ & $\mathrm{LC}$ & tarde & sí & comunidad \\
\hline 31 & Ara macao & guacamaya & $\mathrm{P}$ & $\mathrm{LC}$ & $\begin{array}{l}\text { mañana- } \\
\text { tarde }\end{array}$ & no & $\begin{array}{l}\text { comunidad- casa } \\
\text { y río }\end{array}$ \\
\hline 32 & $\begin{array}{l}\text { Amazona } \\
\text { autumnalis }\end{array}$ & loro & & $\mathrm{LC}$ & mañana & sí & $\begin{array}{l}\text { comunidad- casa } \\
\text { y río }\end{array}$ \\
\hline 33 & $\begin{array}{l}\text { Amazona } \\
\text { farinosa }\end{array}$ & $\begin{array}{l}\text { loro cabeza } \\
\text { azul }\end{array}$ & $\mathrm{P}$ & $\mathrm{LC}$ & mañana & sí & comunidad \\
\hline 34 & $\begin{array}{l}\text { Myiozetetes } \\
\text { similis }\end{array}$ & $\begin{array}{l}\text { pecho } \\
\text { amarillo }\end{array}$ & & $\mathrm{LC}$ & si & sí & $\begin{array}{l}\text { comunidad- casa, } \\
\text { río y milpa }\end{array}$ \\
\hline 35 & Furnariidae & trepatronco & & & & & comunidad \\
\hline 36 & $\begin{array}{l}\text { Psilorhinus } \\
\text { morio }\end{array}$ & pea & & $\mathrm{LC}$ & & sí & $\begin{array}{l}\text { comunidad- casa } \\
\text { y milpa }\end{array}$ \\
\hline 37 & Hirundinidae & golondrina & & & día & sí & comunidad \\
\hline 38 & Parulidae & chipe & & & mañana & sí & comunidad \\
\hline 39 & Thraupidae & tángara & & & mañana & sí & comunidad \\
\hline
\end{tabular}




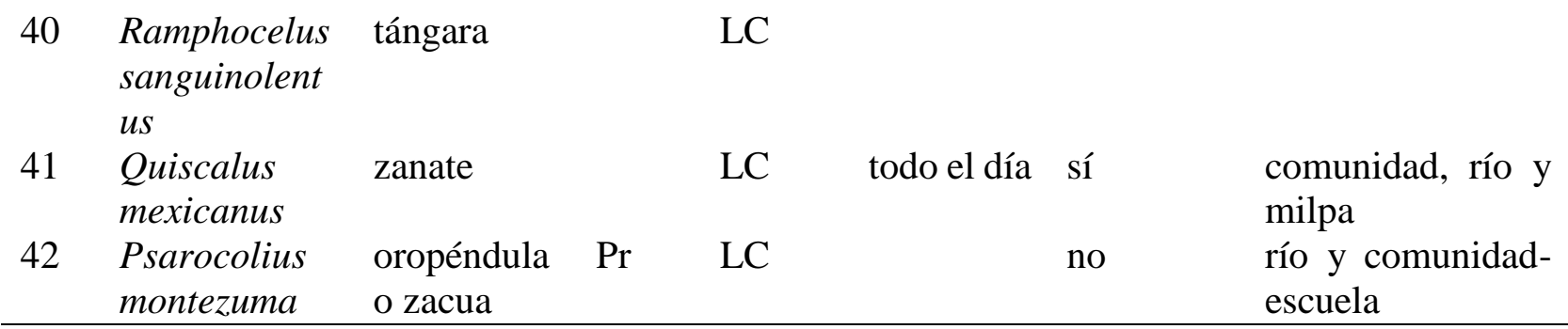

Cuadro 3. Aves observadas en los recorridos en Reforma Agraria, Municipio Marqués de Comillas, Chiapas que los niños no mencionaron o no conocían.

\begin{tabular}{lllll}
\hline & $\begin{array}{l}\text { Nombre que le dan } \\
\text { los niños }\end{array}$ & Nombre científico & $\begin{array}{l}\text { NOM- } \\
\mathbf{0 5 9}\end{array}$ & UICN \\
\hline 1 & maullador gris & Dumetella carolinensis & & LC \\
2 & saltapared común & Troglodytes aedon & & LC \\
3 & mirlo café & Turdus grayi & & LC \\
4 & colorín siete colores & Passerina ciris & Pr & NT \\
\hline
\end{tabular}

Todos los niños han visto de cerca a la mayoría de las aves del listado obtenido debido a que la comunidad es pequeña y se encuentra en medio de la selva y a un lado de la REBIMA (únicamente separadas por el río Lacantún). Los lugares de observación más mencionados, de mayor a menor número de menciones fueron: la selva, la comunidad incluyendo la casa y la escuela, el río, la milpa y los potreros. El 75\% dijeron haber tocado alguna de las siguientes aves: paloma, tucán, guacamaya, cotorro o loro, pijul, pecho amarillo, chéjere y gavilán (ver Cuadro 2).

Por medio del canto, además reconocieron quince aves de un total de 33 grabaciones escuchadas (Cuadro 4).

Cuadro 4. Cantos que reconocen los niños en Reforma Agraria, Municipio Marqués de Comillas, Chiapas.

\begin{tabular}{lll}
\hline \multicolumn{3}{c}{ Aves que reconocen por canto } \\
\hline & $\begin{array}{l}\text { Nombre que le dan } \\
\text { los niños }\end{array}$ & \multicolumn{1}{c}{ Nombre científico } \\
\hline 1 & cojolita & Penelope purpurascens \\
2 & colibrí & Amazilia tzacatl \\
3 & gavilán & Rupornis magnirostris \\
4 & loro & Amazona autumnalis \\
5 & paloma & Patagioenas flavirostris \\
6 & pea & Psilorhinus morio \\
7 & pecho amarillo & Myiozetetes similis \\
8 & perico & Eupsittula canicularis y \\
& & Eupsittula nana \\
\hline
\end{tabular}

No 19, Vol. 9 (2), 2017. ISSN 2007 - 0705, pp.: 660 - 716 


\begin{tabular}{lll}
\hline 9 & pijul & Crotophaga sulcirostris \\
10 & tucán real & Ramphastos sulfuratus \\
11 & tucancillo & Pteroglossus torquatus \\
12 & zacua & Psarocolius montezuma \\
13 & tortolita & Columbina talpacoti \\
\hline
\end{tabular}

Con base en la información obtenida a partir del cuestionario y las entrevistas, así como de las actividades realizadas, se puede afirmar que los niños poseen un detallado conocimiento ecológico. Por ejemplo, con respecto a aspectos alimenticios, saben de cuales árboles y hierbas se alimentan las aves y pueden distinguir de manera general lo que comen: semillas, insectos, flores o frutas (nanche, guanábana, plátano, anona, zapote, mango, guayaba, corozo, punta de la palma de coco, hojas de guarumbo, guatopo, "bolita de mulato" y jobo).

Conocen muchos aspectos sobre la guacamaya ya que es común observarla en esta zona. Los niños conocen su dieta: principalmente nanche (Byrsonima crassifolia), flor de tulipán (Spathodea campanulata), "bolita de mulato" (Bursera simaruba) y fruta del corozo (Bactris minor). Mencionaron además, once aves que se alimentan de frutas, por ejemplo el tucancillo (Pteroglossus torquatus) que se alimenta de anona o el tucán (Ramphastos sulfuratus) de la bolita de palma y ambos también comen nanche. El colibrí se alimenta del néctar de las flores y mencionaron cuatro especies de aves que se alimentan de pescado, siete más que son cazadoras y/o comen otros animales. Identificaron 21 aves que se alimentan de granos y semillas, por ejemplo la paloma morada (Patagioenas flavirostris) que come semilla de guano, o el pijul (Crotophaga sulcirostris) que come maíz (Cuadro 5). También tienen un amplio conocimiento sobre las zonas donde se pueden observar (comunidad, selva, río y montaña), así como características específicas de colores o sonidos que les ayudan a identificarlas. Las aves más mencionadas en este sentido son la guacamaya, el tucán y el loro.

Cuadro 5. Datos relacionados con la alimentación de las aves mencionados por los

\begin{tabular}{ll}
\multicolumn{2}{c}{ niños en Reforma Agraria, Municipio Marqués de Comillas, Chiapas. } \\
\hline Ave & Alimentación \\
\hline águila & pescado \\
búho & carne \\
carpintero & frutas como anona, manzana y plátano \\
chipe & frutas \\
cojolita & cacao \\
colibrí & néctar de flores \\
garza & pescado \\
\hline
\end{tabular}

No 19, Vol. 9 (2), 2017. ISSN 2007 - 0705, pp.: 660 - 716 


\begin{tabular}{|c|c|}
\hline gavilán & carne \\
\hline guacamaya & $\begin{array}{l}\text { nanche, corozo, punta de la palma de coco, } \\
\text { bolita de mulato, hojas de guarumo, flor de tulipán }\end{array}$ \\
\hline halcón & carne \\
\hline loro & frutas \\
\hline martín pescador & pescado \\
\hline momoto & frutas \\
\hline oropéndula & carne \\
\hline paloma rosada & frutas como plátano \\
\hline pea & frutas \\
\hline perico & nanche \\
\hline pijiji & pescado \\
\hline pijul & mariposas, nance y hoja de guarumbo, maíz \\
\hline tangara & frutas \\
\hline tucán & frutas como nanche, anona y bolita de palma \\
\hline tucancillo & frutas como nanche y anona \\
\hline zopilote & carne en descomposición \\
\hline
\end{tabular}

Los niños preguntaron a sus padres y abuelos sobre cuentos o leyendas de aves en la comunidad y acerca de aves agoreras (se les llama así a las aves que avisan sobre algo). El 50\% de ellos mencionaron tres aves que avisan cuando va a llover: el pijul (Crotophaga sulcirostris) "dicen que cuando un pijul se para en palo seco y mira para arriba y canta hace un llamado pidiendo agua, esto anuncia aguacero y le llaman el pájaro que pide agua”, el cuco vaquero (Piaya cayana) y el carpintero (Campephilus guatemalensis), este último también anuncia la muerte "cuando se posa y pica el palo".

\section{Problemáticas}

En cuanto a los problemas que los niños identifican que tienen las aves, aunque en la comunidad está prohibido cazar animales, saben que corren el riesgo de que las maten con rifle, sobre todo por parte de personas que no pertenecen a la comunidad. Algunos niños también les tiran piedras con resortera, las maltratan y tiran sus nidos y huevos.

En cuanto a problemas generados por las aves mencionaron a la zacua (Psarocolius montezuma) porque "hace bulla". Una variedad de especies comen los frutos que las personas consumen como nanches, plátano, mandarina, tamarindo, naranja, guanábana, anona, rambután y mango y por último se tiene a la pea (Psilorhinus morio) que en ocasiones se llega a comer los huevos de las gallinas que tienen en su patio. 
Al realizar una dinámica para identificar soluciones a los problemas y generar compromisos, los niños mencionaron que pueden realizar acciones de cuidado hacia las aves, principalmente evitando violentarlas y cuidar que no las maten otros animales como las serpientes. Es importante notar que no generaron compromisos que involucraran aspectos relacionados con el medio, la perturbación del ambiente o la contaminación, lo que puede indicar que a nivel conceptual no relacionan el problema en ese sentido. Otras respuestas obtenidas de las entrevistas sobre el cuidado que tienen hacia las aves fueron: curarlas cuando se lastiman y posteriormente liberarlas, darles comida y decirles a otros niños que no les peguen con la resortera.

\section{Percepción y valoración}

Relacionan la palabra pájaro con la palabra ave y el $100 \%$ menciona que poseen alas y plumas como característica distintiva, describiéndolos como animales que vuelan. También reconocen algunos depredadores de las aves como la culebra, el tigrillo, el tlacuache y el jaguar.

Demuestran un alto aprecio por las aves, se refieren a ellas como "animales hermosos", les gusta verlas cuando vuelan y les atraen sus plumas de colores.

Las describieron con los adjetivos "buenos y bonitos", mencionaron que son importantes en la naturaleza y para las personas; han visto que en la comunidad cuidan y alimentan a las guacamayas y a los tucanes y que estos constituyen un atractivo visual que atrae al turismo ayudando a la economía de la comunidad. Saben de la importancia de las plumas para elaborar objetos de joyería y tienen la percepción de que en general las aves no hacen nada que pueda dañar a las personas.

"Si no hubiera pájaros estaríamos tristes, no estaría bonito, no podríamos verlos volando, estaría aburrido" son algunas de las palabras que utilizaron para transmitir lo que pasaría si desaparecieran las aves.

En la nube de palabras que representa las frecuencias de mención sobre la percepción, las de mayor repetición se observan más grandes (Figura 2).

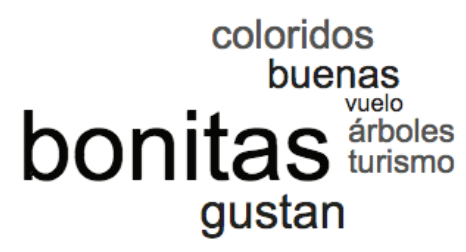

No 19, Vol. 9 (2), 2017. ISSN 2007 - 0705, pp.: 660 - 716 
Figura 2. Nube de palabras que muestra la frecuencia de menciones en las percepciones de los niños en Reforma Agraria, Municipio Marqués de Comillas, Chiapas (elaborado en worditout.com).

\section{Conocimiento en Frontera Corozal}

\section{Especies identificadas y aspectos ecológicos}

En la escuela primaria Leandro Valle se generó un listado con 31 especies de aves, de las cuales once se encuentran en alguna categoría de riesgo según la NOM-059. En esta escuela se registraron seis nombres en Ch'ol (Cuadro 6). En la escuela primaria Jaime Torres Bodet reconocieron también 31 especies de aves, de las cuales seis se encuentran en la NOM-059. Se registraron 25 palabras en Ch'ol para designar a 29 aves distintas (Cuadro 7), esto se debe a que la guacamaya y el quetzal no tienen nombre en Chóol, mientras que otras aves comparten la misma palabra, es decir, existen complejos taxonómicos bajo la misma categoría (Cuadro 8). Se registró también la palabra de Ajtso' para el pavo (Meleagris gallopavo), sin embargo no se anota en la lista debido a que es ave de corral. Otras aves que conocen pero no se agregan al listado debido a que no se encuentran en su comunidad son el cuervo, la gaviota y el canario.

Cuadro 6. Aves que reconocen los niños de $6^{\circ} \mathrm{A}$ y $6^{\circ} \mathrm{B}$ de la primaria Leandro Valle en Frontera Corozal, Municipio de Ocosingo, Chiapas. Ordenados según la clasificación propuesta por la American Ornithologists' Union (AOU, 1998) y sus actualizaciones (AOU, 2015). Las respuestas en negritas corresponden a información diferente obtenida en el subgrupo 2 de $6^{\circ} \mathrm{A}$ y las subrayadas a la información diferente obtenida del subgrupo de $6^{\circ} \mathrm{B}$.

\begin{tabular}{|c|c|c|c|c|c|c|c|c|c|}
\hline & $\begin{array}{l}\text { Nombre } \\
\text { científico }\end{array}$ & $\begin{array}{l}\text { Nombre } \\
\text { que le } \\
\text { dan }\end{array}$ & $\begin{array}{l}\text { NO } \\
\text { M- } \\
059\end{array}$ & UICN & Ch'ol & $\begin{array}{l}\text { Signi- } \\
\text { ficado }\end{array}$ & $\begin{array}{l}\text { Hora } \\
\text { en } \\
\text { que se } \\
\text { obser- } \\
\text { va }\end{array}$ & $\begin{array}{c}\text { Todo el } \\
\text { año }\end{array}$ & $\begin{array}{l}\text { En } \\
\text { dónde se } \\
\text { observa }\end{array}$ \\
\hline 1 & $\begin{array}{l}\text { Tinamus } \\
\text { major }\end{array}$ & perdiz & $\mathrm{A}$ & NT & $\begin{array}{l}\text { Kuluka } \\
\text { b }\end{array}$ & & tarde & sí & $\begin{array}{l}\text { milpa y } \\
\text { selva }\end{array}$ \\
\hline 2 & $\begin{array}{l}\text { Dendrocygna } \\
\text { autumnalis }\end{array}$ & pijiji & & $\mathrm{LC}$ & & & & a veces & río \\
\hline 3 & $\begin{array}{l}\text { * Cairina } \\
\text { moschata }\end{array}$ & $\begin{array}{l}\text { pato de } \\
\text { monte }\end{array}$ & $\mathrm{P}$ & $\mathrm{LC}$ & & & & a veces & $\begin{array}{l}\text { rancho, } \\
\text { río }\end{array}$ \\
\hline 4 & Ortalis vetula & $\begin{array}{l}\text { chacha- } \\
\text { laca }\end{array}$ & & $\mathrm{LC}$ & & & & a veces & casa \\
\hline
\end{tabular}


Conocimiento y percepción de la avifauna en niños de dos comunidades en la selva Lacandona, Chiapas, México: hacia una conservación biocultural

\begin{tabular}{|c|c|c|c|c|c|c|c|c|c|}
\hline 5 & $\begin{array}{l}\text { Penelope } \\
\text { purpurascens }\end{array}$ & cojolita & $\mathrm{A}$ & $\mathrm{LC}$ & $\begin{array}{l}\text { Cox/ } \\
\text { K’ox }^{\prime}\end{array}$ & $\begin{array}{l}\text { Ono- } \\
\text { matop } \\
\text { éyico }\end{array}$ & $\mathrm{d}$ & $\begin{array}{l}\text { a veces/ } \\
\text { tiene su } \\
\text { temporad } \\
\text { a }\end{array}$ & milpa \\
\hline 6 & Crax rubra & faisán & A & VU & & & $\underline{\mathrm{d}}^{\mathrm{d} / \operatorname{tard}}$ & a veces & casa \\
\hline 7 & Bubulcus ibis & garza & & $\mathrm{LC}$ & & & $\mathrm{d}$ & sí & $\begin{array}{l}\text { cerca del } \\
\text { ganado, } \\
\text { río }\end{array}$ \\
\hline 8 & $\begin{array}{l}\text { Cathartes } \\
\text { aura } \\
\text { Coragyps } \\
\text { atratus }\end{array}$ & zopilote & & $\mathrm{LC}$ & & & $\begin{array}{l}\mathrm{d} y \\
\text { tarde/ } \\
\underline{\text { noche }}\end{array}$ & sí & casa, río \\
\hline 9 & $\begin{array}{l}\text { Sarcoramphu } \\
\text { s papa }\end{array}$ & $\begin{array}{l}\text { zopilote } \\
\text { rey }\end{array}$ & $\mathrm{P}$ & $\mathrm{LC}$ & & & d & $\begin{array}{l}\text { sí/a } \\
\text { veces }\end{array}$ & volando \\
\hline $\begin{array}{l}1 \\
0\end{array}$ & $\begin{array}{l}\text { Pandion } \\
\text { haliaetus }\end{array}$ & $\begin{array}{l}\text { águila } \\
\text { pescador } \\
\text { a }\end{array}$ & & $\mathrm{LC}$ & & & & a veces & río \\
\hline $\begin{array}{l}1 \\
1\end{array}$ & Accipitridae & gavilán & & & & & d & sí & casa, río \\
\hline $\begin{array}{l}1 \\
2\end{array}$ & Accipitridae & águila & & & & & d & $\begin{array}{l}\text { sí/a } \\
\text { veces }\end{array}$ & casa, río \\
\hline $\begin{array}{l}1 \\
3\end{array}$ & $\begin{array}{l}\text { Harpia } \\
\text { harpyja }\end{array}$ & $\begin{array}{l}\text { águila } \\
\text { harpía }\end{array}$ & $\mathrm{P}$ & NT & & & & $\overline{\text { a veces }}$ & $\begin{array}{l}\text { no la han } \\
\text { observad } \\
\text { o pero } \\
\text { dicen } \\
\text { que está } \\
\text { en la } \\
\text { selva }\end{array}$ \\
\hline $\begin{array}{l}1 \\
4\end{array}$ & $\begin{array}{l}\text { Columbina } \\
\text { talpacoti }\end{array}$ & tortolita & & $\mathrm{LC}$ & & & d & sí & $\begin{array}{l}\text { casa, } \\
\text { escuela, } \\
\text { río y } \\
\text { milpa }\end{array}$ \\
\hline $\begin{array}{l}1 \\
5\end{array}$ & $\begin{array}{l}\text { Zenaida } \\
\text { asiatica }\end{array}$ & $\begin{array}{l}\text { paloma } \\
\text { de } \\
\text { monte }\end{array}$ & & $\mathrm{LC}$ & Mucuy & & $\begin{array}{l}\frac{\mathrm{d} /}{\text { todo el }} \\
\text { día y } \\
\mathrm{n}\end{array}$ & sí & $\begin{array}{l}\text { casa, } \\
\text { escuela, } \\
\text { río }\end{array}$ \\
\hline $\begin{array}{l}1 \\
6\end{array}$ & Strigidae & búho & & & & & $\underline{\mathrm{d}}$ y $\mathrm{n}$ & $\begin{array}{l}\underline{\text { síla }} \\
\text { veces }\end{array}$ & casa, río \\
\hline $\begin{array}{l}1 \\
7\end{array}$ & $\begin{array}{l}\text { Palabra } \\
\text { genérica }\end{array}$ & $\begin{array}{l}\text { tapacam } \\
\text { i-no }\end{array}$ & & & Puyero & $\begin{array}{l}\text { ono- } \\
\text { mato- } \\
\text { péyic } \\
\text { o }\end{array}$ & $\begin{array}{l}\text { tarde- } \\
\text { noche }\end{array}$ & sí & $\begin{array}{l}\text { milpa- } \\
\text { nido en } \\
\text { el suelo }\end{array}$ \\
\hline $\begin{array}{l}1 \\
8\end{array}$ & Trochilidae & colibrí & & & & & & $\begin{array}{l}\text { sí/primav } \\
\text { era }\end{array}$ & $\begin{array}{l}\text { río, } \\
\text { milpa y } \\
\text { casa }\end{array}$ \\
\hline
\end{tabular}




\begin{tabular}{|c|c|c|c|c|c|c|c|c|c|}
\hline $\begin{array}{l}1 \\
9\end{array}$ & $\begin{array}{l}\text { Pharomachru } \\
\text { s mocinno }\end{array}$ & quetzal & $\mathrm{P}$ & $\mathrm{NT}$ & & & $\begin{array}{l}\text { todo el } \\
\text { día- } \\
\text { tarde/ } \\
\text { noche }\end{array}$ & a veces & selva \\
\hline $\begin{array}{l}2 \\
0\end{array}$ & Alcedinidae & $\begin{array}{l}\text { martin } \\
\text { pescador }\end{array}$ & & & & & & a veces & río \\
\hline $\begin{array}{l}2 \\
1\end{array}$ & $\begin{array}{l}\text { Ramphastos } \\
\text { sulfuratus }\end{array}$ & tucán & A & $\mathrm{LC}$ & & & $\underline{\mathrm{e}}^{\mathrm{d} / \mathrm{tard}}$ & $\begin{array}{l}\text { sí/a } \\
\text { veces/pri } \\
\text { mavera }\end{array}$ & $\begin{array}{l}\text { casa, río } \\
\text { y milpa }\end{array}$ \\
\hline $\begin{array}{l}2 \\
2\end{array}$ & $\begin{array}{l}\text { Campephilus } \\
\text { guatemalensis }\end{array}$ & $\begin{array}{l}\text { carpinter } \\
\text { o }\end{array}$ & $\operatorname{Pr}$ & $\mathrm{LC}$ & & & $\begin{array}{l}\mathrm{d}, \\
\text { todos } \\
\text { los } \\
\text { días }\end{array}$ & sí & $\begin{array}{l}\text { comunid } \\
\text { adcasa, } \\
\text { escuela, } \\
\text { milpa, } \\
\text { río }\end{array}$ \\
\hline $\begin{array}{l}2 \\
3\end{array}$ & Psittasidae & perico & & & & & tarde & sí & \\
\hline $\begin{array}{l}2 \\
4\end{array}$ & Ara macao & $\begin{array}{l}\text { guacama } \\
\text { ya roja }\end{array}$ & $\mathrm{P}$ & $\mathrm{LC}$ & & & $\mathrm{dyn}$ & $\begin{array}{l}\text { sí/ a } \\
\text { veces }\end{array}$ & $\begin{array}{l}\text { casa, } \\
\text { milpa y } \\
\text { comunid } \\
\text { adpasan } \\
\text { volando } \\
\text { en } \\
\text { parejas }\end{array}$ \\
\hline $\begin{array}{l}2 \\
5\end{array}$ & Psittacidae & loro & & & & & $\begin{array}{l}\text { todo el } \\
\text { día }\end{array}$ & $\begin{array}{l}\text { sí /abril y } \\
\text { mayo }\end{array}$ & casa \\
\hline $\begin{array}{l}2 \\
6\end{array}$ & $\begin{array}{l}\text { Amazona } \\
\text { autumnalis }\end{array}$ & $\begin{array}{l}\text { loro } \\
\text { cabeza } \\
\text { roja } \\
\text { (cotorro) }\end{array}$ & & $\mathrm{LC}$ & & & $\begin{array}{l}\frac{\mathrm{d} \mathrm{y}}{\mathrm{n} / \text { todo }} \\
\mathrm{s} \text { los } \\
\text { días }\end{array}$ & sí & selva \\
\hline $\begin{array}{l}2 \\
7\end{array}$ & $\begin{array}{l}\text { Amazona } \\
\text { farinosa }\end{array}$ & $\begin{array}{l}\text { loro } \\
\text { cabeza } \\
\text { azul } \\
\text { (cotorro) }\end{array}$ & $\mathrm{P}$ & $\mathrm{LC}$ & & & $\begin{array}{l}\frac{\mathrm{d} y}{\underline{\mathrm{n}} / \text { todo }} \\
\mathrm{s} \text { los } \\
\text { días }\end{array}$ & $\begin{array}{l}\text { síl abril y } \\
\underline{\text { mayo }}\end{array}$ & $\begin{array}{l}\text { selva, } \\
\text { casa }\end{array}$ \\
\hline $\begin{array}{l}2 \\
8\end{array}$ & $\begin{array}{l}\text { Psilorhinus } \\
\text { morio }\end{array}$ & pea & & $\mathrm{LC}$ & & & $\begin{array}{l}\text { todo el } \\
\text { día }\end{array}$ & a veces & $\begin{array}{l}\text { casa, } \\
\text { milpa }\end{array}$ \\
\hline $\begin{array}{l}2 \\
9\end{array}$ & & $\begin{array}{l}\text { zorzal o } \\
\text { mirlo }\end{array}$ & & $\mathrm{LC}$ & $\begin{array}{l}\mathrm{C}^{\prime} \mathrm{o} \\
\mathrm{c}^{\prime} \mathrm{o} / \\
\mathrm{C}^{\prime} \text { ayo } \\
\mathrm{m}\end{array}$ & $\begin{array}{l}\text { Onom } \\
\text { atopé } \\
\text { yico }\end{array}$ & & sí & $\begin{array}{l}\text { comunid } \\
\text { ad }\end{array}$ \\
\hline $\begin{array}{l}3 \\
0\end{array}$ & Parulidae & chipe & & & $\begin{array}{l}\text { ch’ip } \\
\text { ch’ip }\end{array}$ & $\begin{array}{l}\text { Onom } \\
\text { atopé } \\
\text { yico }\end{array}$ & $\begin{array}{l}\text { todos } \\
\text { los } \\
\text { días }\end{array}$ & sí & $\begin{array}{l}\text { Comunid } \\
\text { ad } \\
\text { escuela } \\
\text { y, milpa }\end{array}$ \\
\hline $\begin{array}{l}3 \\
1\end{array}$ & $\begin{array}{l}\text { Quiscalus } \\
\text { mexicanus }\end{array}$ & zanate & & $\mathrm{LC}$ & & & $\mathrm{dyn}$ & sí & $\begin{array}{l}\text { casa, } \\
\text { palmas } \\
\text { de coco, } \\
\text { milpa }\end{array}$ \\
\hline
\end{tabular}


Cuadro 7. Aves que reconocen los niños de $5^{\circ}$ y $6^{\circ}$ de la primaria Jaime Torres Bodet en Frontera Corozal, Municipio de Ocosingo, Chiapas. Ordenados según la clasificación propuesta por la American Ornithologists' Union (AOU, 1998) y sus actualizaciones (AOU, 2015). Las respuestas en negritas corresponden a información diferente obtenida en el subgrupo 2 de $6^{\circ}$ y las subrayadas a la información diferente obtenida de $5^{\circ}$ grado.

\begin{tabular}{|c|c|c|c|c|c|c|c|c|c|}
\hline & $\begin{array}{l}\text { Nombre } \\
\text { científico }\end{array}$ & $\begin{array}{l}\text { Nombre } \\
\text { que le } \\
\text { dan }\end{array}$ & $\begin{array}{l}\text { NO } \\
\text { M- } \\
059\end{array}$ & $\underset{\mathbf{N}}{\mathbf{U I C}}$ & Ch'ol & $\begin{array}{l}\text { Signifi- } \\
\text { cado }\end{array}$ & $\begin{array}{l}\text { Hora } \\
\text { en que } \\
\text { se } \\
\text { obser- } \\
\text { va }\end{array}$ & $\begin{array}{l}\text { Se ve } \\
\text { todo el } \\
\text { año }\end{array}$ & $\begin{array}{l}\text { En dónde } \\
\text { se observa }\end{array}$ \\
\hline 1 & $\begin{array}{l}\text { Tinamus } \\
\text { major }\end{array}$ & perdiz & $\mathrm{A}$ & NT & $\begin{array}{l}\text { Kuluka } \\
\text { b/ } \\
\text { Kuluka' }\end{array}$ & $\begin{array}{l}\text { onomato } \\
\text { péyico }\end{array}$ & $\mathrm{D}$ & sí & árbol \\
\hline 2 & $\begin{array}{l}\text { Ortalis } \\
\text { vetula }\end{array}$ & $\begin{array}{l}\text { chacha- } \\
\text { laca }\end{array}$ & & $\mathrm{LC}$ & Kel & $\begin{array}{l}\text { onomato } \\
\text { péyico }\end{array}$ & $\mathrm{D}$ & $\begin{array}{l}\text { sí pero } \\
\text { más en } \\
\text { abril, } \\
\text { mayo y } \\
\text { diciem- } \\
\text { bre }\end{array}$ & suelo \\
\hline 3 & Crax rubra & faisán & A & VU & $\begin{array}{l}\text { Chäkmu } \\
\text { ty }\end{array}$ & $\begin{array}{l}\text { Por su } \\
\text { color }\end{array}$ & $\mathrm{D} y \mathrm{n}$ & sí & árbol \\
\hline 4 & $\begin{array}{l}\text { *Phalacrocor } \\
\text { ax brasilianus }\end{array}$ & $\begin{array}{l}\text { pato de } \\
\text { agua }\end{array}$ & & $\mathrm{LC}$ & $\begin{array}{l}\mathrm{Ja}^{\prime} \mathrm{a} \\
\text { pech }\end{array}$ & $\begin{array}{l}\text { Describe } \\
\text { que es de } \\
\text { agua }\end{array}$ & $\begin{array}{l}\text { En las } \\
\text { tardes/ } \\
\mathrm{dy} \mathrm{n}\end{array}$ & sí & agua-río \\
\hline 5 & $N D$ & garza & & & $\begin{array}{l}\text { Ja'al } \\
\text { pech }\end{array}$ & & $\mathrm{D}$ & sí & suelo- río \\
\hline 6 & $\begin{array}{l}\text { Palabra } \\
\text { genérica }\end{array}$ & zopilote & & $\mathrm{LC}$ & Tya'jol & $\begin{array}{l}\text { cabeza } \\
\text { de excre- } \\
\text { mento }\end{array}$ & $\mathrm{D}$ & sí & árbol \\
\hline 7 & $\begin{array}{l}\text { Palabra } \\
\text { genérica }\end{array}$ & águila & & & Xäye' & & $\mathrm{D} y \mathrm{n}$ & sí & árbol \\
\hline 8 & $\begin{array}{l}\text { Palabra } \\
\text { genérica }\end{array}$ & gavilán & & & Xäye' & & $\mathrm{D} y \mathrm{n}$ & sí & árbol \\
\hline 9 & $\begin{array}{l}\text { Patagioenas } \\
\text { nigrirostris }\end{array}$ & $\begin{array}{l}\text { paloma } \\
\text { oscura }\end{array}$ & Pr & $\mathrm{LC}$ & Ujkuts' & $\begin{array}{l}\text { onoma- } \\
\text { topéyico }\end{array}$ & $\mathrm{D}$ & sí & comunidad \\
\hline 10 & $\begin{array}{l}\text { Columbina } \\
\text { talpacoti }\end{array}$ & tortolita & & $\mathrm{LC}$ & $\begin{array}{l}\text { Puruwo } \\
\mathrm{k}\end{array}$ & $\begin{array}{l}\text { onoma- } \\
\text { topéyico }\end{array}$ & $\mathrm{D}$ & sí/mayo & suelo-agua \\
\hline 11 & $\begin{array}{l}\text { Zenaida } \\
\text { asiatica }\end{array}$ & $\begin{array}{l}\text { paloma de } \\
\text { monte }\end{array}$ & & $\mathrm{LC}$ & Mucuy & $\begin{array}{l}\text { onoma- } \\
\text { topéyico }\end{array}$ & $\mathrm{D}$ & sí & $\begin{array}{l}\text { camina, } \\
\text { suelo, árbol } \\
\text { y casas }\end{array}$ \\
\hline 12 & $\begin{array}{l}\text { Palabra } \\
\text { genérica }\end{array}$ & lechuza & & & Kuj & $\begin{array}{l}\text { onoma- } \\
\text { topéyico }\end{array}$ & & & $\begin{array}{l}\text { árbol } \\
\text { comunidad }\end{array}$ \\
\hline 13 & $\begin{array}{l}\text { Palabra } \\
\text { genérica }\end{array}$ & tecolote & & & Kuj & $\begin{array}{l}\text { onoma- } \\
\text { topéyico }\end{array}$ & & & $\begin{array}{l}\text { árbol } \\
\text { comunidad }\end{array}$ \\
\hline 14 & $\begin{array}{l}\text { Palabra } \\
\text { genérica }\end{array}$ & búho & & & Kuj & $\begin{array}{l}\text { onoma- } \\
\text { topéyico }\end{array}$ & $\mathrm{N}$ & sí & $\begin{array}{l}\text { árbol } \\
\text { comunidad }\end{array}$ \\
\hline 15 & $\begin{array}{l}\text { Streptoprocne } \\
\text { zonaris }\end{array}$ & $\begin{array}{l}\text { Golondrina } \\
\text { (es un } \\
\text { vencejo) }\end{array}$ & & $\mathrm{LC}$ & Wilis & $\begin{array}{l}\text { Describe } \\
\text { su } \\
\text { compor- } \\
\text { tamiento } \\
\text { de vuelo }\end{array}$ & D y n & sí & río \\
\hline
\end{tabular}


Rodríguez-Ramírez, Martha del C. et al.

\begin{tabular}{|c|c|c|c|c|c|c|c|c|c|}
\hline 16 & $\begin{array}{l}\text { Palabra } \\
\text { genérica }\end{array}$ & colibrí & & & $\begin{array}{l}\text { Ts'uñuñ } \\
/ \\
\text { Ts'uñun }\end{array}$ & $\begin{array}{l}\text { onoma- } \\
\text { topéyico }\end{array}$ & $\mathrm{D}$ & $\begin{array}{l}\text { sí- } \\
\text { prima- } \\
\text { vera }\end{array}$ & $\begin{array}{l}\text { árbol- } \\
\text { volando }\end{array}$ \\
\hline 17 & $\begin{array}{l}\text { Palabra } \\
\text { generica }\end{array}$ & trogón & & & Mank'u & & & & selva \\
\hline 18 & $\begin{array}{l}\text { Pharomachrus } \\
\text { mocinno }\end{array}$ & quetzal & $\mathrm{P}$ & NT & $\begin{array}{l}\text { No hay } \\
\text { palabra }\end{array}$ & & D & no & $\begin{array}{l}\text { selva, no } \\
\text { está en la } \\
\text { comunidad }\end{array}$ \\
\hline 19 & $\begin{array}{l}\text { Pteroglossus } \\
\text { torquatus }\end{array}$ & tucancillo & & & Pinzik' & $\begin{array}{l}\text { onoma- } \\
\text { topéyico }\end{array}$ & $\begin{array}{l}\text { Cuando } \\
\text { llueve }\end{array}$ & sí & $\begin{array}{l}\text { arboles, } \\
\text { selva y } \\
\text { comunidad }\end{array}$ \\
\hline 20 & $\begin{array}{l}\text { Ramphastos } \\
\text { sulfutarus }\end{array}$ & tucán & A & $\mathrm{LC}$ & Päm & & D & sí & árbol \\
\hline 21 & $\begin{array}{l}\text { Melanerpes } \\
\text { aurifrons }\end{array}$ & cheje & & $\mathrm{LC}$ & $\underline{\text { Ch'ejku }}$ & $\begin{array}{l}\text { onoma- } \\
\text { topéyico }\end{array}$ & D & sí & árbol \\
\hline 22 & $\begin{array}{l}\text { Dryocopus } \\
\text { lineatus }\end{array}$ & $\begin{array}{l}\text { carpintero } \\
\text { lineado }\end{array}$ & & & $\bar{T}$ Tselel & & & & $\begin{array}{l}\text { comunidad } \\
\text { en arboles }\end{array}$ \\
\hline 23 & $\begin{array}{l}\text { Campephilus } \\
\text { guatemalensis }\end{array}$ & $\begin{array}{l}\text { carpintero } \\
\text { pico } \\
\text { plateado }\end{array}$ & & & $\underline{\text { Tselel }}$ & & & & $\begin{array}{l}\text { comunidad } \\
\text { en arboles }\end{array}$ \\
\hline 24 & $\begin{array}{l}\text { Palabra } \\
\text { genérica }\end{array}$ & perico & & & $\begin{array}{l}\text { Tyuyu'/ } \\
\text { Tyujyu’ }\end{array}$ & $\begin{array}{l}\text { onoma- } \\
\text { topéyico }\end{array}$ & D & mayo & $\begin{array}{l}\text { selva, } \\
\text { volando, } \\
\text { comunidad }\end{array}$ \\
\hline 25 & Ara macao & $\begin{array}{l}\text { guacama- } \\
\text { ya }\end{array}$ & $\mathrm{P}$ & $\mathrm{LC}$ & $\begin{array}{l}\text { No hay } \\
\text { palabra }\end{array}$ & & D & sí- abril & árbol \\
\hline 26 & $\begin{array}{l}\text { Amazona } \\
\text { autumnalis }\end{array}$ & $\begin{array}{l}\text { loro (les } \\
\text { llaman } \\
\text { también } \\
\text { cotorro) }\end{array}$ & & $\mathrm{LC}$ & Ujrich' & $\begin{array}{l}\text { onoma- } \\
\text { topéyico }\end{array}$ & D & $\begin{array}{l}\text { sí- } \\
\text { primave } \\
\text { ra }\end{array}$ & árbol \\
\hline 27 & $\begin{array}{l}\text { Myiozetetes } \\
\text { similis }\end{array}$ & $\begin{array}{l}\text { pecho } \\
\text { amarillo }\end{array}$ & & $\mathrm{LC}$ & $\begin{array}{l}\text { Pajsa'l } \\
\text { Pasa' }^{\prime}\end{array}$ & & D & & comunidad \\
\hline 28 & $\begin{array}{l}\text { Psilorhinus } \\
\text { morio }\end{array}$ & chara pea & & $\mathrm{LC}$ & Peya' & $\begin{array}{l}\text { onoma- } \\
\text { topéyico }\end{array}$ & & & \\
\hline 29 & Parulidae & chipe & & & Ch'ip & $\begin{array}{l}\text { onoma- } \\
\text { topéyico }\end{array}$ & D & sí & árbol \\
\hline 30 & Dives dives & $\begin{array}{l}\text { tordo } \\
\text { cantor (lo } \\
\text { confun-den } \\
\text { con zanate) }\end{array}$ & & & Wachin & & D y n & sí & $\begin{array}{l}\text { palmas, } \\
\text { árbol }\end{array}$ \\
\hline 31 & $\begin{array}{l}\text { Psarocolius } \\
\text { montezuma }\end{array}$ & $\begin{array}{l}\text { oropéndu- } \\
\text { la }\end{array}$ & $\operatorname{Pr}$ & $\mathrm{LC}$ & $\begin{array}{l}\text { K'u'bul } \\
\text { / ku'bul }\end{array}$ & & D & & comunidad \\
\hline
\end{tabular}

Cuadro 8. Complejos taxonómicos identificados en Ch’ol en FC, Municipio de Ocosingo, Chiapas.

\begin{tabular}{|c|c|c|}
\hline $\begin{array}{l}\text { Palabra en } \\
\text { Chóol }\end{array}$ & Orden & Aves mencionadas \\
\hline Xäye & $\begin{array}{l}\text { Accipitriformes } \\
\text { Falconiformes }\end{array}$ & Águila, gavilán \\
\hline Kuj & Strigiformes & Lechuza, tecolote y búho \\
\hline Tselel & $\begin{array}{l}\text { Piciformes de la familia } \\
\text { Picidae }\end{array}$ & $\begin{array}{l}\text { Carpintero lineado y carpintero } \\
\text { plateado }\end{array}$ \\
\hline
\end{tabular}

No 19, Vol. 9 (2), 2017. ISSN 2007 - 0705, pp.: 660 - 716 


\begin{tabular}{llll}
\hline Tyuyu $^{\prime}$ & $\begin{array}{l}\text { Psittaciformes de menor Pericos } \\
\text { tamaño }\end{array}$ \\
Ujrich & $\begin{array}{l}\text { Psittaciformes de mayor Loros } \\
\text { tamaño }\end{array}$ & & \\
\hline
\end{tabular}

En ambas escuelas de FC los niños reconocen a las aves por cuatros aspectos generales, en primer lugar aspectos morfológicos: la forma del cuerpo, pico, patas o alas, el color, las plumas, en segundo lugar el tamaño; en tercer lugar los etológicos: el canto y la conducta (como el modo de volar y descender) y por último porque son animales que ponen huevos. Dentro de los aspectos morfológicos que les ayudan a reconocerlas se encuentran principalmente los colores, el tamaño y la forma, y en los etológicos sonidos, cantos y llamados (Anexo 2).

En ambas escuelas el porcentaje de niños que habla lengua Ch'ol es muy alto (Cuadro 9), en cada grupo también hubo un niño que dijo hablar tseltal. Los niños utilizan la palabra "Ch'e" en Cholol para referirse de manera general a las aves pequeñas y medianas, aunque en realidad los adultos utilizan la misma palabra para referirse a la especie mímido gris o maullador gris (Dumetella carolinensis) que es un ave migratoria.

Cuadro 9. Porcentaje de niños hablantes de lengua Ch’ol y/o español en los grupos de las primarias LV y JTB donde se realizó la investigación, Frontera Corozal, Municipio de Ocosingo, Chiapas.

\begin{tabular}{lll}
\hline Lengua & Leandro Valle & Jaime Torres Bodet \\
\hline Ch'ol y español & $86 \%$ & $88 \%$ \\
Solo español & $13 \%$ & $12 \%$ \\
\hline
\end{tabular}

En esta comunidad reconocieron a catorce aves por medio de los cantos (Cuadro 10) de un total de 33 grabaciones escuchadas.

Cuadro 10. Cantos que reconocen los niños en Frontera Corozal, Municipio de Ocosingo, Chiapas.

\begin{tabular}{lll}
\hline \multicolumn{3}{c}{ Ave que reconocen por canto } \\
\hline 1 & colibrí & Amazilia tzacatl \\
2 & gavilán & Rupornis magnirostris \\
3 & halcón & Falco rufivirgatus \\
4 & loro & Amazona autumnalis \\
5 & loro & Amazona farinosa \\
6 & paloma & Zenaida asiatica \\
7 & pea & Psilorhinus morio \\
\hline
\end{tabular}




\begin{tabular}{lll}
\hline 8 & perico & Eupsittula nana \\
9 & tortolita & Columbina talpacoti \\
10 & tucán real & Ramphastos sulfuratus \\
11 & tucancillo & Pteroglossus torquatus \\
12 & oropéndula & Psarocolius montezuma \\
13 & zanate & Quiscalus mexicanus \\
14 & zorzal & Turdus grayi \\
\hline
\end{tabular}

En cuanto a los aspectos ecológicos, en ambas escuelas conocen varios hábitos alimenticios y el lugar donde observan frecuentemente a las aves. En el Cuadro 11 y Cuadro 12, están marcadas con asterisco (*) las especies que reportaron que comen masa, lo que corrobora que las han alimentado en su casa como mascotas.

Cuadro 11. Aspectos de alimentación que conocen los niños de la escuela Leandro Valle en Frontera Corozal, Municipio de Ocosingo, Chiapas. "Son alimentadas con masa.

\begin{tabular}{|c|c|c|}
\hline Ave & Dieta & Donde vive \\
\hline águila & insectos, carne, pescado & $\begin{array}{l}\text { selva y comunidad, la pescadora } \\
\text { en el río }\end{array}$ \\
\hline búho & carne, insectos, ratones & $\begin{array}{l}\text { árboles, es nocturno en la } \\
\text { comunidad después de las } 5 \mathrm{pm}\end{array}$ \\
\hline carpintero & $\begin{array}{l}\text { insectos, frutas, capulín, gusanos, tamarindo, } \\
\text { naranja y chapay }\end{array}$ & $\begin{array}{l}\text { árboles que no tienen hoja, huecos } \\
\text { de palos en el árbol }\end{array}$ \\
\hline *chachalaca & semillas, insectos, gusanos, maíz & selva no en la comunidad \\
\hline & $\begin{array}{l}\text { semillas, insectos como moscas } \\
\text { semillas y hojas }\end{array}$ & $\begin{array}{l}\text { árboles de la comunidad } \\
\text { selva }\end{array}$ \\
\hline colibrí & miel de flor & $\begin{array}{l}\text { aquí en la comunidad, en las } \\
\text { ramas }\end{array}$ \\
\hline faisán & semillas y maíz & ejido Betel y milpa \\
\hline garza & $\begin{array}{l}\text { insectos, pescado, lombriz, camarón, } \\
\text { gusanos, algunas comen garrapatas del } \\
\text { ganado }\end{array}$ & $\begin{array}{l}\text { selva y lagunas y ríos, monte, } \\
\text { posada en palos y otras están en el } \\
\text { potrero }\end{array}$ \\
\hline gavilán & carne, pollo y huevos & \\
\hline guacamaya & $\begin{array}{l}\text { semillas, frutas, color, canto, por el sonido } \\
\text { cuando vuela }\end{array}$ & selva árboles \\
\hline *loro & $\begin{array}{l}\text { semillas, frutas, brotes de flores, vainas, maíz } \\
\text { quebrado, nueces, capulín, jojolín, grillos, } \\
\text { hojas }\end{array}$ & $\begin{array}{l}\text { huecos de árboles, selva y } \\
\text { mascota }\end{array}$ \\
\hline $\begin{array}{l}\text { martín } \\
\text { pescador }\end{array}$ & Pescado & río \\
\hline *paloma & $\begin{array}{l}\text { semillas, insectos, maíz quebrado, gusanos, } \\
\text { moscas, hormigas, ranas muertas, capulín, } \\
\text { grillos }\end{array}$ & en la comunidad \\
\hline
\end{tabular}




\begin{tabular}{|c|c|c|}
\hline $\begin{array}{l}\text { pato de } \\
\text { monte }\end{array}$ & semillas, insectos & en el agua, en la selva \\
\hline pea & semillas, insectos & bordes de bosques \\
\hline *perdiz & semillas & selva y milpa \\
\hline *perico & semillas & árboles selva \\
\hline pijiji & semillas, insectos, pescado, lombrices, maíz & selva y comunidad \\
\hline quetzal & semillas, insectos, frutas & selva \\
\hline tapacamino & semillas & suelo, nido en tierra \\
\hline tortolita & semillas & comunidad \\
\hline tucán & semillas, frutas, insectos y gusanos & árboles selva \\
\hline zanate & $\begin{array}{l}\text { semillas, insectos, maíz, hormigas, gusanos, } \\
\text { moscas, sapos, culebras, grillos, frijol, ratón }\end{array}$ & árboles de coco, palmas \\
\hline zopilote & $\begin{array}{l}\text { carne en descomposición, carroña, cosas } \\
\text { muertas como el pollo y el ganado }\end{array}$ & $\begin{array}{l}\text { árboles en la comunidad, por la } \\
\text { altura a la que vuela }\end{array}$ \\
\hline zopilote rey & carne podrida & selva \\
\hline zorzal & insectos, popó, gusanos y capulín & árboles y monte \\
\hline
\end{tabular}

Cuadro 12. Aspectos de alimentación que conocen los niños de la escuela Jaime Torres Bodet en Frontera Corozal, Municipio de Ocosingo, Chiapas, las aves con asterisco* mencionaron que también se alimentan de masa.

\begin{tabular}{|c|c|c|}
\hline Ave & Dieta & Donde vive \\
\hline águila & carne, pollo, ratones, culebras y pescado & $\begin{array}{l}\text { comunidad, río, milpa y en la } \\
\text { selva }\end{array}$ \\
\hline búho & carne, ratones, insectos & comunidad \\
\hline carpintero & lombriz, coco, insectos, gusanos & $\begin{array}{l}\text { comunidad en huecos de árboles, } \\
\text { casa, milpa }\end{array}$ \\
\hline chachalaca & semillas, frutas como el nanche, maíz & $\begin{array}{l}\text { árboles de la selva, comunidad, } \\
\text { milpa }\end{array}$ \\
\hline chipe & frutas, insectos, gusanos & comunidad, casa, escuela \\
\hline colibrí & $\begin{array}{l}\text { néctar de las flores, miel de plátano, polen } \\
\text { de la flor, insectos }\end{array}$ & $\begin{array}{l}\text { comunidad en los árboles, casa, } \\
\text { escuela }\end{array}$ \\
\hline faisán & semillas, frutas, ramón y camote, hojas & milpa \\
\hline garza & $\begin{array}{l}\text { insectos, pescado como la sardina, rana, } \\
\text { cangrejo, camarón, lombriz, y gusano }\end{array}$ & selva, río, comunidad, milpa \\
\hline gavilán & carne, pescado y culebra & selva, montañas y comunidad \\
\hline golondrina & hojas de árbol y miel de flor & comunidad, río \\
\hline guacamaya & frutas, semillas y hojas & $\begin{array}{l}\text { árboles de la selva, pasan volando } \\
\text { en parejas por su casa y escuela, } \\
\text { milpa }\end{array}$ \\
\hline loro & frutas, semillas, maíz y frijol, , tortillas & $\begin{array}{l}\text { en la comunidad, casa, escuela, } \\
\text { milpa y en la selva }\end{array}$ \\
\hline *paloma & maíz, frijol, semillas y fruta de palo, & $\begin{array}{l}\text { casas de la comunidad, en las } \\
\text { láminas, en el suelo, escuela, } \\
\text { milpa, río y en arboles de la selva }\end{array}$ \\
\hline
\end{tabular}




\begin{tabular}{|c|c|c|}
\hline $\begin{array}{l}\text { pato de } \\
\text { agua }\end{array}$ & pescados como la sardina y mojarra & $\begin{array}{l}\text { río, donde hay agua, comunidad y } \\
\text { selva }\end{array}$ \\
\hline perdiz & semillas, maíz y fruta, como el plátano & árboles, selva y comunidad \\
\hline perico & semillas y frutas & selva y comunidad \\
\hline quetzal & Frutas & en la selva \\
\hline tecolote & carne, pollo, pescado, gusanos & árboles, selva y comunidad \\
\hline *tortolita & semillas, frutas, maíz, capulín y gusanos & $\begin{array}{l}\text { árboles, casa, escuela comunidad, } \\
\text { milpa, río y en la selva }\end{array}$ \\
\hline tucán & semillas y frutas, ramón y hojas & $\begin{array}{l}\text { selva, río y árboles de la } \\
\text { comunidad, casa, escuela, milpa }\end{array}$ \\
\hline tucancillo & frutas, maíz & árboles selva, comunidad, milpa \\
\hline zanate & $\begin{array}{l}\text { frutas, semillas, maíz, frijol, rutas, insectos } \\
\text { y caracol }\end{array}$ & $\begin{array}{l}\text { comunidad en los arboles, en las } \\
\text { palmas, casa, escuela, río, milpa }\end{array}$ \\
\hline zopilote & carne en descomposición & $\begin{array}{l}\text { árboles más altos, en la } \\
\text { comunidad, río }\end{array}$ \\
\hline
\end{tabular}

En la escuela primaria Leandro Valle se recabaron cuatro cuentos, dos sobre quetzales, uno del pájaro carpintero, uno del tucán. Adicionalmente se documentaron dos historias de aves agoreras: “cuando los pájaros gritan mucho llaman a la lluvia” y otra sobre un águila negra que "cuando pasa gritando y se posa en algún terreno es señal de que algo malo va a pasar". Las aves que anuncian desgracias son los búhos, por lo tanto algunas personas piensan que son malos.

En la escuela primaria Jaime Torres Bodet las historias recabadas fueron sobre el pavo real, el colibrí y el pájaro carpintero, no se documentaron aves agoreras.

La mayoría de las historias en ambas escuelas fueron consultadas por los niños en internet debido a que los padres y abuelos no conocían ninguna.

\section{Problemáticas}

Con relación a la problemática que tienen las aves se pueden mencionar cuatro ejes principales detectados por los niños: el daño directo (las matan, las lastiman, etc.), el daño ambiental (contaminación, tala, quema), el daño por uso (caza para venta, comer, etc.) y las causas naturales (enfermedades, depredación). Con respecto a los problemas que generan se resumen en daño a las cosechas y consumo de frutos o del alimento de sus aves de corral, en rasguños o "picar" y dejar desechos en las casas (Cuadro 13). Se generaron compromisos por escuela posteriores a identificar acciones con las que pueden contribuir al cuidado y conservación de las aves (Cuadro 14). De manera general tienen que ver con el cuidado directo de las aves pero también logran relacionar el 
cuidado del ambiente, conservación de la selva, tala de árboles, incendios, entre otros, con el bienestar de las aves.

Cuadro 13. Problemática identificada por niños en Frontera Corozal, Municipio de Ocosingo, Chiapas.

\begin{tabular}{|c|c|c|}
\hline & Jaime Torres Bodet & Leandro Valle \\
\hline $\begin{array}{l}\text { Problemas } \\
\text { que tienen } \\
\text { las aves }\end{array}$ & $\begin{array}{l}\text { quema de parcelas } \\
\text { las matan con los rifles o resorteras } \\
\text { contaminan el agua y la naturaleza } \\
\text { arrancan sus frutas } \\
\text { talan los árboles donde van a dejar sus } \\
\text { huevos } \\
\text { les da enfermedad } \\
\text { trafican con ellos, los hacen mascotas } \\
\text { las comen } \\
\text { les quitan las plumas y el pico }\end{array}$ & $\begin{array}{l}\text { las queman cuando queman su área } \\
\text { las matan con balas con pistolas y } \\
\text { rifles } \\
\text { les tiran con resortera } \\
\text { tala de árboles } \\
\text { las envenenan } \\
\text { viene el perro y las come } \\
\text { agarran pájaros bebés } \\
\text { tiran piedras } \\
\text { ponen trampas } \\
\text { les quitan las plumas } \\
\text { machetean su área } \\
\text { las venden como mascotas } \\
\text { se las comen }\end{array}$ \\
\hline $\begin{array}{l}\text { Problemas } \\
\text { que generan } \\
\text { las aves }\end{array}$ & $\begin{array}{l}\text { Dañan los cultivos, se comen el maíz y } \\
\text { frijol, } \\
\text { la chachalaca arranca la flor, } \\
\text { se comen la fruta como el mango, las } \\
\text { naranjas y el zapote, } \\
\text { los zanates sacan las semillas del } \\
\text { huerto, } \\
\text { pican, rasguñan, } \\
\text { entran a la casa y hacen travesuras }\end{array}$ & $\begin{array}{l}\text { dejan deshechos en cualquier lado, } \\
\text { comen la fruta, } \\
\text { comen la milpa, } \\
\text { los cotorros hablan mucho, } \\
\text { se comen el alimento de los pollitos, } \\
\text { pican }\end{array}$ \\
\hline
\end{tabular}

Cuadro 14. Compromisos adquiridos para conservar a las aves por los niños de las escuelas LV y JTB en Frontera Corozal, Municipio de Ocosingo, Chiapas.

\begin{tabular}{ll}
\hline Leandro Valle & Jaime Torres Bodet \\
\hline cuidarlos & no tirar piedras \\
no matar a las aves & no quemar la selva \\
no tirarles piedras & no talar árboles \\
alimentarlos & quitar las resorteras \\
no maltratarlos & no tirar o molestar sus nidos \\
no tumbar sus árboles & no matarlas, no lastimarlas, no molestarlas \\
no molestarlas & no contaminar la selva ni el agua que toman \\
convivir con ellos & no comerlas \\
no quemarles su área & cuidar su hábitat \\
no sacar sus nidos & darle de comer a los pájaros \\
no sacarlos de su área & sembrar más árboles frutales \\
\hline
\end{tabular}


no molestar a sus bebés

no romper ni robar sus huevos

no destruir a las aves

vigilar si están bien

ayudarlos para que no estén en peligro de extinción

ayudarlos si están atrapados en una trampa no vender las aves

cuidarlas

demandar a los que cazan pájaros

no romper sus huevos

no capturarlas

no tirar basura

\section{Percepción y valoración}

Los niños de esta comunidad al igual que en Reforma Agraria tienen un alto aprecio por las aves, se refieren a ellas como animales hermosos, les gusta verlas cuando vuelan y les atraen sus plumas de colores. Esto pareciera contradictorio ya que en estas comunidades se sigue presentando el daño con resorteras, sin embargo cada vez hay mas conciencia y saben que no deben lastimarlas.

En la escuela Leandro Valle la mayoría de los niños se perciben como poco conocedores de los diferentes tipos de aves, sus cantos, hábitat y su alimentación, además de que piensan que son poco aptos para diferenciarlas, cosa que en la práctica y por medio de los presentes resultados no se sustenta. Dicen haber tocado loros, tortolitas, guacamaya y palomas que coinciden con los animales mencionados como mascotas.

El $100 \%$ identifica las alas y las plumas como características distintivas de las aves, las relacionan con mascotas, se refieren a ellas como "animales bonitos" que viven en la selva particularmente en los árboles. Los lugares donde dicen observarlas de mayor a menor frecuencia son: la selva (incluyendo la Reserva), los árboles, la comunidad, la casa, la milpa y algunos niños dijeron que las observan prácticamente en todas partes.

Perciben a las aves como útiles, sobre todo como mascotas. Los principales depredadores de las aves que conocen son el águila, los felinos, las serpientes, los perros y las personas.

La mayoría mencionaron que las aves les gustan, que les agradan sus cantos y que son bonitas: "Son bonitas, chulas, dan felicidad a la vida” Paulina, once años. "Los pájaros no son malos como otros animales, no son bravos, los quiero porque no hacen daño y no muerden”.

El 100\% de los niños dicen que las aves son buenas y son importantes y que si no existieran se sentirían tristes.

"Sin los pájaros no hubiera felicidad” Jessica.

“En el mundo habría un silencio sin cantos hermosos” Mareli, once años. "Las aves dan belleza al mundo" Diana doce años 
"Los pájaros dan alegría, ellos dan vida a los paisajes" Unicela, once años.

"Está bien que haya pájaros porque le dan un ambiente feliz" Aleydis, once años.

Los niños reportaron que sus padres les han hablado de las aves pero no así en la escuela, dijeron que les gustaría aprender más y hacer caminatas de observación. La mayoría piensa que hay que cuidarlas porque son importantes y saben que la contaminación afecta a este grupo de organismos y los coloca en peligro, también hacen hincapié en que si hay muchas aves llegará el turismo.

La forma en la que reportan que las cuidan es dándoles comida y agua, sin dañar la selva, sembrando matas de plantas que puedan comer y diciéndole a otros niños que no las deben matar. "Si no estuvieran acá los pájaros no se verían bonitos en todas partes" Ronaldo. "En mi comunidad hay bastantes pájaros que vuelan muy bonito y su canto es muy hermoso" Aida.

$\mathrm{Al}$ analizar las frecuencias de mención sobre la percepción para construir una nube de palabras (Figura 3) se encontraron con mayor repetición: alegría, bonitas, canto, árboles, hermosas, buenas, naturaleza, gustan y compañía.

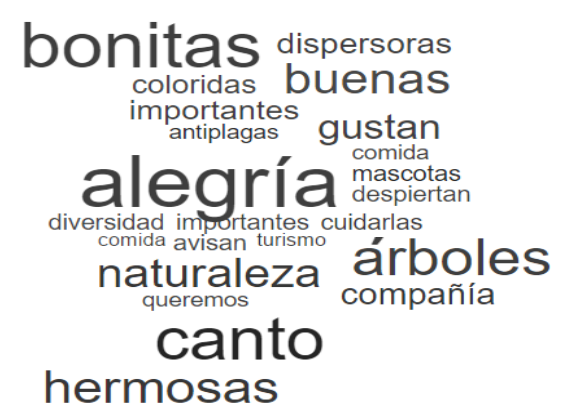

Figura 3. Nube de palabras que muestra la frecuencia de menciones de la percepción de los niños en la escuela Leandro Valle, Municipio de Ocosingo, Chiapas (elaborado en worditout.com).

En lo referente a la escuela primaria Jaime Torres Bodet, el 100\% reconoce que las aves son animales que tienen alas, plumas y que vuelan, al igual que en la escuela Leandro Valle asumen que conocen poco sobre ellas y sus cantos, aunque dicen tener más conocimiento sobre lo que comen. Los lugares más mencionados para observarlas fueron la selva, los solares, la milpa, la comunidad, la casa, la escuela y los árboles. Los depredadores de las aves que conocen son el águila, los felinos como el ocelote, las culebras y los perros. 
Las perciben como útiles porque pueden ser mascotas, muestran una alta apreciación por sus cantos y la mayoría piensa que son bonitas.

"Son importantes porque le dan belleza al mundo" Diana, doce años, Jaime Torres Bodet.

La mayoría piensa que hay que cuidarlas, en la escuela les hablan poco o nada sobre ellas y a todos les gustaría aprender más y realizar caminatas de observación.

"A mi si me gustaría porque así nos motivarían para no asesinar a los pobres pajaritos y para cuidarlos y respetarlos... yo deseo hacer caminatas porque ahí podríamos haber visto como serían sus características" Adán, once años.

Consideran que la avifauna está en peligro por las actividades humanas y reconocen que la contaminación y pérdida de hábitat por quemas y tala están afectando las poblaciones de aves. Los padres les han hablado más que los profesores sobre este grupo de organismos. Hacen mucho hincapié en el atractivo visual que los turistas pueden encontrar si se conservan las aves. Dijeron haber tocado tortolitas y loros principalmente, seguidos por el tucán y la guacamaya. La mayoría dijo que si no existieran las aves se pondrían tristes:

"Sin ellos la selva estaría triste, no habría pájaros para comer ni quien lleve la semilla por toda la selva" Ignacio, once años.

"Yo pienso que es bonito tener a esas aves cerca" Adán, diez años.

"Mi casa se ve bonita porque hay muchos pájaros y árboles...Si se mueren no va a haber compañía" Brayan, once años.

“Los pájaros son bonitos, ¿para qué matarlos? Mejor tomarles una foto y listo” Deyli, once años.

Como actividades que lastiman a las aves mencionaron principalmente que las matan, contaminan el ambiente, queman y talan los arboles. Las niñas por lo general no usan la resortera pero algunos niños sí lo hacen. Saben que se pueden utilizar las plumas sin embargo ellos no las han utilizado. El 100\% piensa que son "buenas" porque "no les hacen nada" y que la forma de cuidarlas se puede dividir en tres categorías, cuidado directo (no matarlos, darles comida, no destruir sus nidos), cuidado del medio (cuidar la selva, no talar árboles, no quemar), acciones de concientización (decirle a otras personas que las cuiden) y no les gusta que algunas personas los cacen para venderlos. Muchos de los niños le otorgan un alto valor intrínseco, mencionando que por el hecho de estar en la naturaleza merecen cuidados:

"Debemos decirles a las personas que no los maltraten y saber que forman parte de la naturaleza" Deyli, once años. 
"Hay que decir a la comunidad que no les hagan daño porque son seres vivos, hay que respetar".

Puede existir una influencia en los hábitos de uso de las aves y sus partes debido a que son comunidades que se encuentran cercanas a las ANP y tienen varias prohibiciones, como la caza, la extracción de especies, entre otras.

En la nube de palabras sobre la percepción (Figura 4) las que más resaltaron fueron: buenas, bonitas, canto, árboles, comer, alegría, diversidad, compañía y gustan.

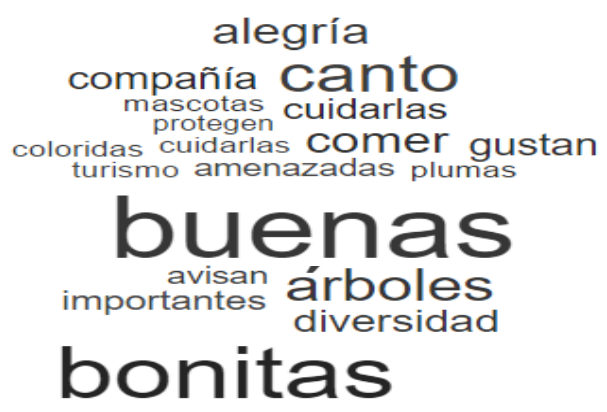

Figura 4. Nube de palabras que muestra la frecuencia de menciones de la percepción de los niños en la escuela Jaime Torres Bodet, Municipio de Ocosingo, Chiapas (elaborado en worditout.com).

\section{Aves favoritas y en peligro}

En entrevistas, cuestionarios, dibujos y fichas elaborados por los niños, las aves con mayor frecuencia de mención en ambas comunidades fueron la guacamaya y el tucán. Las aves favoritas en ambas comunidades son la guacamaya, el loro y la paloma; y las que identifican y coinciden en peligro de extinción son el tucán y la guacamaya (Cuadro 15).

Cuadro 15. Aves favoritas y en peligro con mayor frecuencia de mención por los niños de RA, Municipio Marqués de Comillas y FC, Municipio de Ocosingo, Chiapas.

\begin{tabular}{llll}
\hline & RA & LV & JTB \\
\hline $\begin{array}{l}\text { Aves más } \\
\text { mencionadas }\end{array}$ & guacamaya y & $\begin{array}{l}\text { guacamaya, loro, } \\
\text { tucán, paloma, } \\
\text { carpintero, } \\
\text { tortolita y faisán colibrí, }\end{array}$ & $\begin{array}{l}\text { tucán, guacamaya, loro, } \\
\text { torico, paloma, carpintero, } \\
\text { tortolita, quetzal, colibrí, } \\
\text { zanate, garza y águila. }\end{array}$ \\
$\begin{array}{l}\text { Aves } \\
\text { favoritas }\end{array}$ & $\begin{array}{l}\text { guacamaya, } \\
\text { perico, loro, } \\
\text { paloma }\end{array}$ & $\begin{array}{l}\text { quetzal, guacamaya, loro, } \\
\text { tucán, tortolita, colibrí y } \\
\text { paloma }\end{array}$ & $\begin{array}{l}\text { tortolita, } \\
\text { colibrí, carpintero y paloma }\end{array}$ \\
\hline
\end{tabular}




\begin{tabular}{lllll}
\hline $\begin{array}{l}\text { Aves en } \\
\text { peligro }\end{array}$ & $\begin{array}{l}\text { tucán, guacamaya } \\
\text { o loro } \\
\text { amenazadas }\end{array}$ & $\begin{array}{l}\text { guacamaya, tucán } \\
\text { quetzal }\end{array}$ & $\begin{array}{l}\text { quetzal, guacamaya, tucán y } \\
\text { paloma y tortolita porque se } \\
\text { las comen }\end{array}$ \\
\hline
\end{tabular}

En RA por medio de 18 dibujos se documentaron otras aves que les gustan; en orden de mayor a menor aparición éstos son el colibrí, el chéjere, el tucán, la paloma y el águila, cuco vaquero, tucancillo, hocofaisán, cotorro, tángara, guaquillo y águila arpía. Esta última aunque no la han visto les llama la atención porque les han platicado que es muy grande.

En FC la información obtenida por medio de 64 dibujos demuestra que las principales aves preferidas de mayor a menor fueron el tucán (16), la guacamaya (7), el quetzal (6), carpintero (6), perico (5), dodo (6), tucancillo esmeralda (4), paloma (3), loro (2), garza (2), gavilán (2), águila, chipe, pijiji, zopilote y cotorra serrana (estas últimas con un dibujo cada uno). Cabe resaltar que hay aves que dibujaron porque las tienen en su libro de texto como el quetzal, el dodo (Raphus cucullatus que se encuentra extinto), el tucancillo esmeralda y la cotorra serrana.

Referente a las fichas elaboradas de su ave favorita, la mayor parte de la información la obtuvieron de internet y las aves de las que escribieron con mayor frecuencia fueron la paloma, el loro, la guacamaya, la tortolita, el tucán y el colibrí, las cuatro primeras son sus preferidas debido a que las tienen como mascotas. Identifican guacamayas, tucán y quetzal como aves en peligro de extinción.

En la escuela JTB las aves dibujadas por 50 niños en 133 dibujos de mayor a menor aparición fueron: la guacamaya (15), loro (15), tucán (14), tortolita (6), paloma (6), colibrí (5), perico (5), tucancillo esmeralda (5), carpintero (4), quetzal (4), zanate (3), dodo (3), cotorra serrana (2), tángara (2), zopilote y águila (con un dibujo cada uno). Las características que les gustan están relacionadas con el color del plumaje y los sonidos que hacen, en cuanto a los loros les gusta que hablen y que ofrecen compañía. Tanto la cotorra serrana, el tucancillo esmeralda y el dodo los dibujaron porque los observaron en su libro de texto, esto también se observó en la escuela LV. Las fichas de su ave favorita en su mayoría se referían a la guacamaya, el tucán, el loro, la tortolita, el colibrí y el carpintero. Es interesante que hayan realizado también fichas sobre el quetzal y la cotorra serrana porque ambos se encuentran en su libro de texto aunque no los han visto en la comunidad. Las aves que mencionan en peligro de extinción son el quetzal, la guacamaya y el tucán, aunque la paloma y las tortolitas las matan mucho. 
En FC se realizó un taller de cierre y se les preguntó que aprendieron con las actividades y las charlas, la mayoría mencionó que conocieron la importancia que tienen las aves en el ecosistema ya que dispersan semillas y esto ayuda a reforestar, controlar plagas y que algunas ayudan en la polinización, lugares donde viven y algunos nombres que no conocían y que además ellos las pueden proteger.

De manera general para ambas comunidades y con las ideas obtenidas de las diversas actividades y herramientas, se construyeron categorías de valoración y se crearon puntos de enlace entre lo mencionado por los niños (Figura 5).

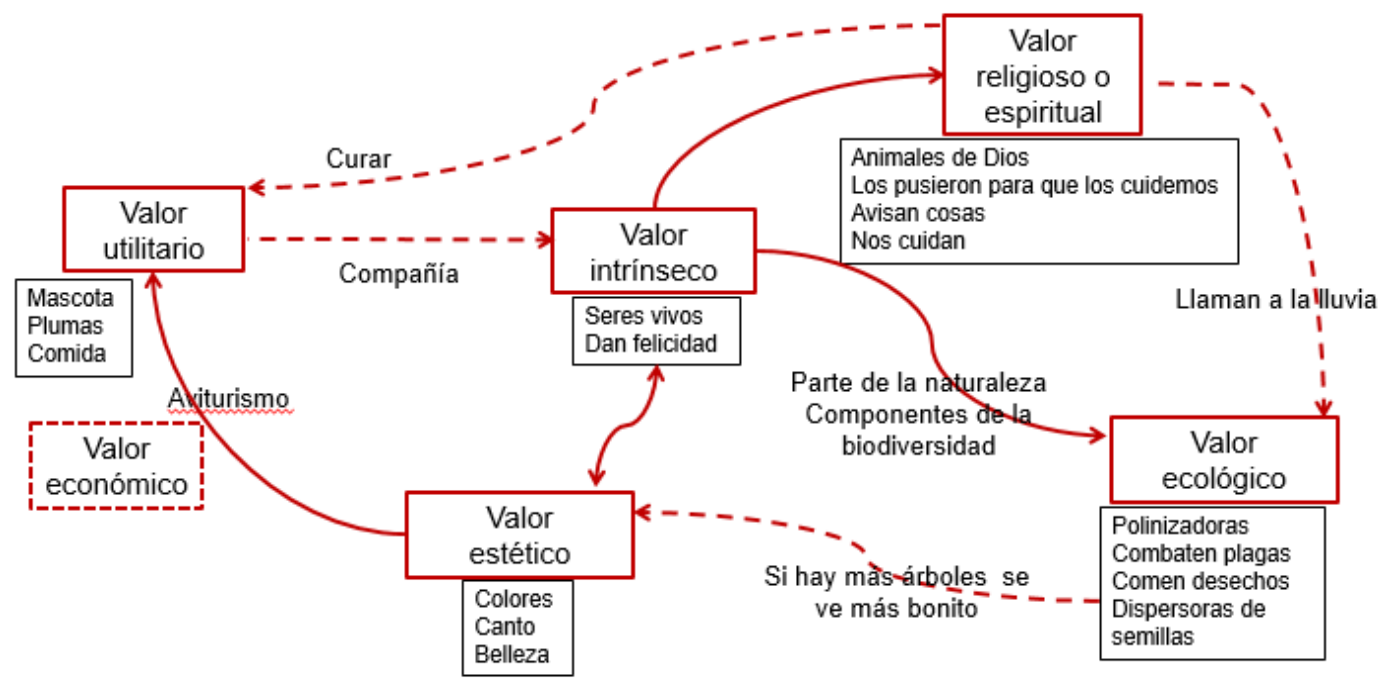

Figura 5. Categorías de valoración que dan los niños a las aves en RA y FC, las líneas discontinuas muestran las relaciones no enunciadas por ellos pero están presentes.

\section{Usos que dan a las aves}

En Reforma Agraria se registraron tres aves comestibles, ocho con uso ornamental (las plumas que encuentran en el suelo las utilizan para hacer aretes y atrapasueños) y once como mascota. Desconocen aves con uso medicinal y dicen conocer los demás usos por las comunidades de Pico de Oro y López Mateos, ya que en la comunidad no está permitido agarrar a los animales. La que llegan a tener como mascota es porque está herida y una vez recuperada la liberan (Cuadro 16).

En Frontera Corozal se registraron quince aves comestibles y catorce como mascotas, los principales son los loros y los pericos que por lo general recogen en la milpa cuando son pequeños. Once aves tienen uso ornamental, se utilizan las plumas para limpiar el fogón y elaborar artesanías 
como collares, aretes, diademas, atrapasueños, flechas y adornar sombreros (Cuadro 17).

Cuadro 16. Usos de las aves mencionados por los niños en Reforma Agraria, Municipio de Marqués de Comillas, Chiapas, asterisco *las han visto en las comunidades Pico de Oro y López Mateos.

\begin{tabular}{llll}
\hline Comestible & $*$ Compañía & Ornamental (plumas) & Medicinal \\
\hline paloma & loro y perico & guacamaya- aretes & loro \\
perico & guacamaya & tucán- atrapasueños & guacamaya \\
loro & tucán & pavo real & pecho amarillo \\
& paloma & pavo & \\
& pecho amarillo & tucancillo & \\
& tucancillo & loro- aretes & \\
colibrí & pijul & \\
pijiji & & \\
& zanate & & \\
& pijul & & \\
& & & \\
\end{tabular}

Cuadro 17. Usos de las aves mencionados por los niños en Frontera Corozal, Municipio de Ocosingo, Chiapas.

\begin{tabular}{|c|c|c|c|c|c|c|c|}
\hline Comestible & $\begin{array}{l}\text { Es- } \\
\text { cue- } \\
\text { la }\end{array}$ & Compañía & $\begin{array}{l}\text { Esc } \\
\text { ue } \\
\text { la }\end{array}$ & $\begin{array}{l}\text { Ornamental } \\
\text { (plumas) }\end{array}$ & $\begin{array}{l}\text { Es- } \\
\text { cuela }\end{array}$ & Medicinal & $\begin{array}{l}\text { Es- } \\
\text { cue- } \\
\text { la }\end{array}$ \\
\hline $\begin{array}{l}\text { tortolita } \\
\text { asado } \\
\text { en mole }\end{array}$ & LV & perico & $\mathrm{LV}$ & $\begin{array}{l}\text { chachalaca- para } \\
\text { limpiar el fogón y } \\
\text { el polvo }\end{array}$ & LV & $\begin{array}{l}\text { pájaro negro- si le } \\
\text { pegas el dolor se le } \\
\text { pasa a la persona }\end{array}$ & $\mathrm{LV}$ \\
\hline $\begin{array}{l}\text { paloma } \\
\text { en caldo }\end{array}$ & LV & $\begin{array}{l}\text { guaca } \\
\text { maya }\end{array}$ & LV & loro- aretes & LV & $\begin{array}{l}\text { Loro- cuando los } \\
\text { niños pequeños no } \\
\text { pueden hablar, lo } \\
\text { comen o lo toman } \\
\text { en caldo }\end{array}$ & LV \\
\hline $\begin{array}{l}\text { pato de monte } \\
\text { mole, en } \\
\text { estofado }\end{array}$ & LV & tucán & LV & pavo real- adorno & LV & $\begin{array}{l}\text { perdiz- cuando } \\
\text { están enfermos del } \\
\text { estómago }\end{array}$ & LV \\
\hline $\begin{array}{l}\text { carpintero } \\
\text { asado }\end{array}$ & LV & paloma & LV & $\begin{array}{l}\text { guacamaya- } \\
\text { pulseras, } \\
\text { diademas, aretes y } \\
\text { atrapasueños }\end{array}$ & LV & pato de monte & LV \\
\hline $\begin{array}{l}\text { pijiji } \\
\text { mole } \\
\text { entomatado }\end{array}$ & LV & $\begin{array}{l}\text { tortolit } \\
\mathrm{a}\end{array}$ & LV & $\begin{array}{l}\text { tucán- collares, } \\
\text { aretes, } \\
\text { atrapasueños, } \\
\text { también utilizan } \\
\text { el pico }\end{array}$ & LV & $\begin{array}{l}\text { zanate- para que } \\
\text { salga cabello, } \\
\text { utilizan la sangre y } \\
\text { la cabeza. Se mata } \\
\text { al zanate y se } \\
\text { bañan con su }\end{array}$ & JTB \\
\hline
\end{tabular}




\begin{tabular}{|c|c|c|c|c|c|c|c|}
\hline mucuy & $\mathrm{LV}$ & colibrí & LV & quetzal & LV & $\begin{array}{l}\text { sangre, sirve para } \\
\text { prevenir canas } \\
\text { pájaros pequeños- } \\
\text { cuando "les echan } \\
\text { brujo", la sangre } \\
\text { del corazón la } \\
\text { toman y la untan en } \\
\text { el cuerpo }\end{array}$ & JTB \\
\hline loro & LV & loro & LV & pijiji & LV & $\begin{array}{l}\text { guacamaya- } \\
\text { utilizan la pluma }\end{array}$ & JTB \\
\hline tucán & LV & pijiji & LV & paloma & LV & $\begin{array}{l}\text { tucán- utilizan la } \\
\text { pluma }\end{array}$ & JTB \\
\hline chachalaca & LV & garza & LV & $\begin{array}{l}\text { tortolita- aretes y } \\
\text { diademas }\end{array}$ & LV & $\begin{array}{l}\text { águila-utilizan la } \\
\text { pluma }\end{array}$ & JTB \\
\hline zorzal & LV & faisán & LV & faisán & LV & $\begin{array}{l}\text { colibrí- lo comen } \\
\text { en caldo para } \\
\text { convulsiones y } \\
\text { ataques }\end{array}$ & JTB \\
\hline faisán & LV & $\begin{array}{l}\text { chachal } \\
\text { aca }\end{array}$ & LV & tucán & LV & $\begin{array}{l}\text { loro y perico- en } \\
\text { caldo para que los } \\
\text { niños pequeños } \\
\text { puedan empezar a } \\
\text { hablar }\end{array}$ & JTB \\
\hline guacamaya & LV & quetzal & LV & $\begin{array}{l}\text { faisán- adornos } \\
\text { para el cabello, en } \\
\text { bailables y } \\
\text { atrapasueños }\end{array}$ & JTB & & \\
\hline perdiz & LV & águila & LV & $\begin{array}{l}\text { guacamaya- } \\
\text { adorno, lujo de la } \\
\text { casa, plumas del } \\
\text { ala para limpiar }\end{array}$ & JTB & & \\
\hline cojolita & LV & $\begin{array}{l}\text { carpint } \\
\text { ero }\end{array}$ & LV & $\begin{array}{l}\text { loro- cuando la } \\
\text { gente baila se lo } \\
\text { pone de adorno en } \\
\text { la cabeza }\end{array}$ & JTB & & \\
\hline $\begin{array}{l}\text { tortolita } \\
\text { asada } \\
\text { en taco } \\
\text { en caldo }\end{array}$ & JTB & $\begin{array}{l}\text { tucán- } \\
\text { por su } \\
\text { pico } \\
\text { colorad }\end{array}$ & $\begin{array}{l}\text { JT } \\
\text { B }\end{array}$ & $\begin{array}{l}\text { tucán- se usa la } \\
\text { cola como adorno } \\
\text { (ñej) y su pico en } \\
\text { collares }\end{array}$ & JTB & & \\
\hline $\begin{array}{l}\text { loro } \\
\text { en caldo } \\
\text { con arroz } \\
\text { asado- } \\
\text { el loro cabeza } \\
\text { blanca }\end{array}$ & JTB & $\begin{array}{l}\text { o y } \\
\text { grande } \\
\text { guaca } \\
\text { maya }\end{array}$ & $\begin{array}{l}\text { JT } \\
\text { B }\end{array}$ & gavilán & JTB & & \\
\hline
\end{tabular}




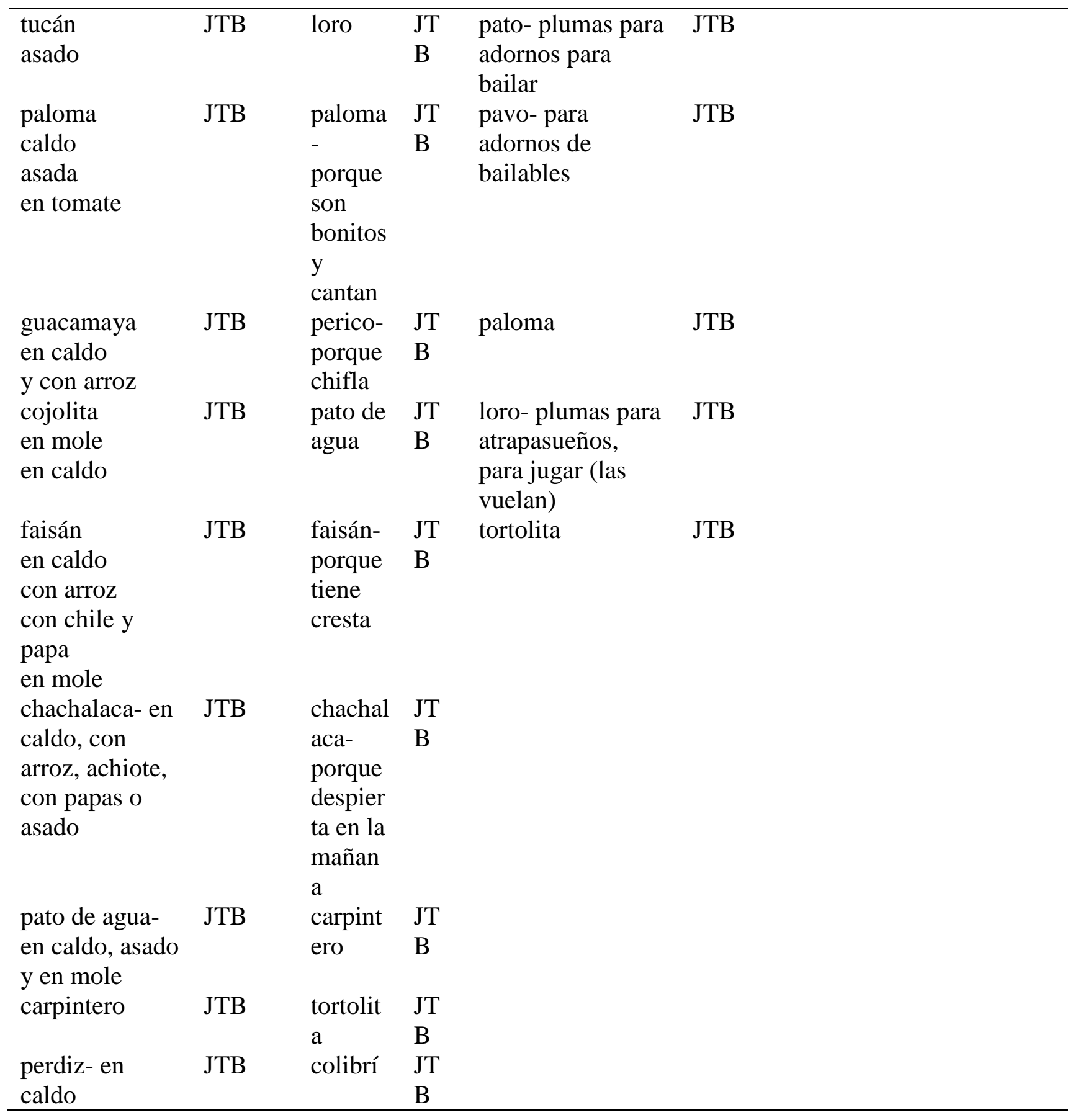

\section{ANP y CONANP}

La pérdida de recursos naturales es notable y alarmante aunque han visto un cambio en la forma de pensar de los niños en los últimos años, ahora son más conscientes sobre la conservación gracias a los cambios en planes de estudio, y ya hay menos niños que usan resorteras. La mayoría de los niños desconoce lo que es un ANP y que ellos viven en zona de influencia, aunque en Reforma 
Agraria cuatro niños ya habían escuchado que viven en una y en Frontera Corozal un par sabía que están cerca de la Reserva.

Al indagar sobre el conocimiento que tienen los niños de las ANP en FC, todos desconocen que viven en un área de influencia del ANP y la mayoría no sabe lo que son excepto algunos que dicen que "es donde se protege a los pájaros" en otras palabras "es una parte de la selva que está protegida, que está toda enmallada y ahí llegan turistas a observar a todas las aves" Jocelyn. "ANP son los que cuidan a las aves y ven que no las maten" Ronaldo.

"Ahí sí es ANP porque hay muchos pájaros y algunos están en peligro de extinción, entonces cuidamos a la reserva para que haya más pájaros" Juan Daniel.

"Una reserva es donde casi el gobierno lo protege por ser suyo, para que no invadan su propiedad", Juan, once años.

Los profesores de la escuela JTB mencionan que la CONANP ha realizado talleres y actividades con los niños sobre temas de conservación ambiental, pero el último fue hace tres años.

En entrevista con un funcionario de la CONANP relacionado con el trabajo comunitario de la REBIMA se corroboró que, en efecto, llevan a cabo actividades como talleres o pláticas con las comunidades de la región sin embargo en Frontera Corozal hace tiempo que no trabajan con las escuelas y en Reforma Agraria no han tenido ninguna participación. En esta institución han escuchado sobre la diversidad biocultural pero no saben mucho al respecto.

"Realmente hay actividades que no se adecuan a cada cultura, se hace la misma en todas, hace falta integrar esa parte y tomar en cuenta las diferentes etnias para poder adecuar los programas...lo deberíamos de hacer pero siento que todavía nos hace falta desarrollarlo".

Con los niños de Frontera Corozal se planean y llevan a cabo actividades de educación ambiental con las escuelas, aunque no de forma frecuente, como parte del "Programa de Conservación de Especies en Riesgo" (PROCER). Éstas se realizan en la segunda mitad del año o los últimos cuatro meses. Hay personas de vigilancia comunitaria que realizan algunos talleres de forma esporádica. El trabajo de la CONANP ha tratado de abarcar los diferentes grados de escolaridad en esta comunidad (primaria, secundaria y CECyTECH) pero no siempre lo logran.

En Frontera Corozal y mayormente en Reforma Agraria no se ha trabajado mucho con los niños debido a un sesgo institucional, ya que aunque es área de influencia este ejido en particular busca sus proyectos por cuenta propia y otros ejidos cercanos son trabajados por la Asociación Civil "Natura y Ecosistemas Mexicanos" por lo tanto, se entiende que está cubierta y prefieren 
trabajar del otro lado donde no hay quién lo haga.

Es común que la gente de las comunidades de zona de influencia haya escuchado de la REBIMA, la gente tiene muy presente que del otro lado del río Lacantún está la Reserva “Reforma Agraria es una comunidad que tiene mucha conciencia en general y los niños seguramente tienen mucho conocimiento por su entorno, se le da mucho conservar", funcionario de la CONANP.

El representante de la CONANP menciona que una limitante para integrar el CT a las actividades institucionales con el apoyo de los habitantes, es la diversidad debido a que existe una gama de distintas historias en la región y algunas poblaciones son más recientes que otras y aunque la parte de la Comunidad Lacandona está sufriendo una pérdida de su cultura aún conservan manejos que han ayudado a la conservación de la zona. Hablando de Frontera Corozal hay una guerra entre los saberes tradicionales y prácticas, por ejemplo de la ganadería que tanto en esta comunidad como en Nueva Palestina están cambiando mucho el ambiente.

"Hay comunidades como Reforma Agraria que son chinantecos que vienen de un lugar donde también había selva y tienen una cuestión de aprovechar los recursos naturales pero sin agotarlos, pero igual hay comunidades mestizas que vienen de otro tipo de ecosistemas como bosques templados que al parecer no sabían cómo aprovechar la selva y optaron por ganadería y empezaron a talar mucho" (Funcionario de la CONANP).

La recomendación en materia de conservación por parte de la CONANP es que las comunidades que tienen ese conocimiento lo puedan promover para que no se pierda porque causan menor impacto en la selva y que esto permee a las comunidades que no lo tienen.

"Hay varias comunidades que tienen milpas tradicionales de los choles o lacandones que a lo mejor se podrían promover en otro tipo de comunidades y frenar este avance de la ganadería" (Funcionario de la CONANP).

\section{Discusión}

\section{Conocimiento}

Tanto en Reforma Agraria como en Frontera Corozal los niños reconocen y admiran a las aves, en particular en el ejido de RA existe gran respeto hacia el medio natural; aunque los fundadores pertenecientes a la Chinantla (en Oaxaca) se dedicaron, en una primera instancia, a hacer uso de la tierra exclusivamente para la ganadería ya que desconocían en parte la flora y la fauna y tenían necesidad de obtener recursos (Cano, 2013, 42).

No 19, Vol. 9 (2), 2017. ISSN 2007 - 0705, pp.: 660 - 716

- 696 - 
En fechas más recientes esta comunidad reconoció la importancia de la conservación y el cuidado de los recursos naturales, practicando ciertas actividades sustentables y realizando un ordenamiento ecológico. Sus propuestas se realizan a partir de acuerdos internos y se da un seguimiento de las actividades planeadas siempre con una visión sustentable, cuestión que ha sido permeada hacia los niños que tienen presentes las normas y restricciones de la comunidad. El proyecto más exitoso que llevan a cabo es el de la Conservación de la Guacamaya Escarlata (Ara macao), que se inició hace más de 11 años, con un planteamiento inicial de colocar nidos artificiales y tomar datos para conocer más sobre la especie (Gobierno del Estado de Chiapas Secretaría de Desarrollo Social, 2006, 6) y a partir de éste han obtenido algunos beneficios, por ejemplo dinero procedente del ecoturismo. La relación de los niños con su entorno se ve favorecida también por el tamaño pequeño de la comunidad y por lo tanto la mayoría de las especies de aves del listado se pueden observar entre las casas; si a esto le sumamos que a la orilla se encuentra el río Lacantún hay gran presencia de estos organismos que realizan actividades cercanas a fuentes de agua, por lo que es fácil observarlas. En Frontera Corozal esto no ocurre en el mismo grado ya que, al ser un poblado más grande y estar más alejado de la selva, tiene menor presencia de aves entre las casas, razón que podría explicar que reconocen un menor número de aves que en RA.

Los resultados son similares a lo encontrado en la comunidad de Playón de la Gloria, comunidad vecina de RA (Yunes-Jiménez, 2015, 51) donde los niños reconocieron 39 aves. En la presente investigación se documentaron 42 aves en RA y 31 en cada una de las dos escuelas de FC. Se encontraron además varias coincidencias entre estos estudios, por ejemplo el que los niños han construido su conocimiento sobre la avifauna a partir de las observaciones cotidianas y la trasmisión oral principalmente por parte de sus padres. En Playón, al igual que en RA, el ave de la que conocen más aspectos es la guacamaya, ya que se observa con mayor frecuencia en la zona y se trata de una especie con gran atractivo visual además de ser el ave más representativa y que atrae a muchos turistas.

Aunque la pérdida del CT es el resultado de muchas variables en juego, uno de los aspectos importante que incide en su preservación es el acceso a la información. Este aspecto es más notorio en FC donde los niños cuentan con acceso a internet y muchas de las tareas asignadas fueron consultadas en ese medio (información externa a la comunidad), y aunado a la falta de un enfoque biocultural e intercultural del sistema educativo, pudiera dar como resultado una pérdida de sus 
conocimientos locales. Valdría la pena realizar una aproximación a los conocimientos en grupos de otras edades dentro de las mismas comunidades para comparar los resultados.

\section{Percepción y valoración}

Ambos estudios coinciden también en que la totalidad de los niños mencionan su gusto por las aves y que los lugares donde las observan con mayor frecuencia son la selva y su casa, además de que las consideran importantes principalmente porque les brindan alegría. En FC, las aves también fueron mencionadas como importantes por la compañía que brindan, es decir, las aves aumentan el bienestar personal y cultural, además son aceptadas por su valor estético (MacKinnon 2004, 37; Villaseñor y Manzano 2003, 381). Este valor y fascinación hacia las aves también se reporta para las cinco etnias que estudiaron Núñez-García y colaboradores $(2012,28)$ en el estado de Oaxaca. Romero-González $(2013,44)$ menciona que los niños en comunidades rurales observan a las aves principalmente en los árboles, lugar que también fue frecuentemente mencionado (56\%) en las comunidades estudiadas.

La adquisición del CT se da principalmente a través de la familia, se ha demostrado que para los niños es natural adquirirlo en el entorno familiar y reforzarlo durante el juego cotidiano, el cuidado de los animales y las labores de cosecha (Hunn 2002, 610, 611). Esto es notorio en RA donde los niños fueron capaces de identificar aves agoreras e historias contadas por sus padres y/o abuelos; aunque tratándose de comunidades con gran turismo (en especial RA) también llegan a escuchar a los guías comunitarios de los que adquieren otros conocimientos que se complementan con los obtenidos en la cotidianeidad. La situación en FC es diferente ya que la comunidad es más grande, con menos vegetación y el turismo llega al MNY y no tanto a la comunidad.

En RA los niños reconocen gran cantidad de aves y aspectos ecológicos, como las interacciones entre las aves y las plantas con las que se alimentan, sin embargo, la parte asociada al conocimiento en lengua indígena chinanteca se está perdiendo y solo algunos adultos conservan la lengua. Por el contrario en FC son pocos los niños, si acaso un par, que no hablan Ch'ol, por esto fue posible obtener la mayoría de los nombres de las aves del listado en esta lengua, principalmente en la primaria bilingüe JTB. La mayoría de estos nombres son onomatopéyicos (81\%), le siguen los de origen etológico (13\%) y relacionados a aspectos físicos (4\%).

En la lista anotada de Hull y Fergus $(2011,55-88)$ de un estudio realizado en Tila y en una comunidad de la periferia de Kokija ' (a diez kilómetros de Tila), ambas localizadas en la región 
de la selva lacandona, en el estado de Chiapas, México, se encontraron coincidencias en las palabras para denominar a las especies de aves, aunque con algunas variaciones en la forma de la escritura para algunos nombres en Ch'ol que se documentaron en FC, esto se debe probablemente a la llamada "variante de Tila" de las comunidades con las que ellos trabajaron.

En FC tienen claro que existe una conexión entre la perturbación y contaminación del medio y la conservación de los organismos, y como propuestas para la conservación mencionan acciones que no sólo involucran un daño directo hacia los organismos sino que integran las necesarias para proteger su hábitat. Esto es similar a lo reportado por Yunes-Jiménez $(2014,46)$ y Guirao-Cruz y colaboradores $(2012,33)$. En RA parecieran no tener clara esta relación ya que se enfocaron únicamente a proponer acciones directas como no matarlas, no lastimarlas, no tirar sus nidos, etc., quizá se deba a que en esa comunidad la conservación del ambiente es alta y pudiera parecer que no se requieren más acciones al respecto o a que hay niños que realizan esas acciones pero son conscientes del daño y por lo tanto saben que si dejaran de hacerlas ayudarían a conservar a las aves.

Romero-González $(2013,18)$ y Yunes-Jiménez $(2014,41)$ reportaron que los niños obtienen principalmente el CT sobre las aves en sus casas, lo cual se observa también en las comunidades del presente estudio, ya que en la escuela no se abordan como tal. En ambas investigaciones reconocen a la guacamaya y el quetzal como aves en peligro de extinción al igual que los niños de RF y FC. Uno de los problemas que enfrentan las aves en comunidades de la selva Lacandona es la cacería, cabe mencionar que en RA la caza está prohibida y existe un alto compromiso con la conservación de los organismos, no así en FC donde aunque no está permitida la caza los habitantes aún realizan esta práctica ocasionalmente.

Al igual que lo reportado por Romero-González (2013) que analizó la percepción de los niños sobre las aves en la zona de los altos de Chiapas, la mayoría de los niños en RA y FC no reconocen que las aves puedan causar daños significativos, a excepción de que se comen las cosechas o ensucian con sus desechos al pasar volando, en general definen a las aves como "bonitas" y "muy importantes". Se encontraron diferencias notorias en otros aspectos de dicho trabajo, ya que en zonas rurales relacionaban los problemas que enfrentan las aves como "directos no antrópicos" y en esta investigación los relacionan en mayor medida a peligros causados por las personas o "directos antrópicos". Por otra parte en el mismo estudio, en zonas rurales no mencionan acciones concretas para protegerlas, a diferencia de RA y FC donde hicieron diversas propuestas 
de participación que los involucra directamente para conservar a las aves. Los niños les dan tanto un valor intrínseco y estético, como utilitario, pero casi todos desconocen los atributos ecológicos que poseen estos organismos aunque identifican muchos aspectos sobre su alimentación.

Se han propuesto diversas categorías de valoración sobre la fauna silvestre. Siguiendo la propuesta de Pérez-Gil $(1995,14)$, tanto en RA como en FC se encontraron los siguientes valores: valor de uso directo como mascotas y de uso indirecto como recreación; valor de cambio como mascotas, para elaborar artesanías y como atractivo para el turismo ecológico; valor de existencia (intrínseco) como seres vivos, que poseen gran belleza y estética, que tienen características místicas o religiosas y forman parte de una herencia cultural, ligados a leyendas, mitos e historias.

\section{Usos}

El conocimiento que adquieren está influenciado por la experiencia propia y cotidiana de acompañar a los padres a su trabajo en el campo, en especial los niños (varones). Otro valor que le otorgan a estos organismos es el de avisar sobre fenómenos meteorológicos; en varias partes del país algunas aves y sus cantos son considerados como indicadores de cambios climáticos como la presencia de lluvia. Otros grupos, como los zapotecos, también relacionan a las aves con el clima (Núñez-García et al. 2012, 22, 27) o que llaman a la lluvia como el águila, las golondrinas o los cuervos (Aldasoro-Maya, 2012, 217). Aunque en RA y FC no mencionaron a las mismas especies, sí se refirieron al llamado de lluvia por parte de las aves. Otros grupos indígenas de Chiapas que utilizan a las aves para predecir el clima son los tsotsiles, los tseltales y los tojolabales (GuerreroMartínez y Serrano-González 2012, 30,31). También se cree que las aves pueden ser portadoras de malos presagios. Las aves agoreras son comunes en la cultura mexicana, en el caso de RA y FC al tecolote o búho se le considera señal de que algo malo ocurrirá, esto es una constante en otros estudios similares (Alcántara 2003, 89, 124, 125; Hull y Fergus 2011, 46; Aldasoro-Maya 2012, 218 y Rivero-Romero et al. 2016, 6), cabe mencionar que dichos estudios se realizaron con población adulta.

Bajo la propuesta de Pérez-Gil $(1995,12)$ se determina que existe una utilización no consuntiva. Por ejemplo el atractivo que tienen las aves para el turismo que acude a observarlas, el uso de las plumas que recogen y utilizan con fines ornamentales y lúdicos, en particular las de guacamayas, pericos, loros, gavilanes y tucanes (Jiménez-Díaz et al. 2014, 96; Yunes-Jiménez 2015, 49 y Alcántara 2003, 124). Esto también se ha reportado entre los Lacandones. El pico del 
tucán en FC, al igual que en otros grupos, se utiliza ocasionalmente con fines ornamentales (Alcántara 2003, 124; Jiménez-Díaz et al. 2014). Algunos de los usos dados a las plumas que reportan los niños en FC son como adorno para bailables, para hacer joyería como aretes, elaborar atrapasueños y para sombreros; también se utilizan para limpiar el fogón. Aunque no se puede asegurar que no exista la cacería con el fin de obtener las plumas, al respecto no se obtuvo información, en cuyo caso se hablaría de uso consuntivo, junto con el uso como mascota que sí se registró. Considerando lo anterior se puede decir que las aves son vulnerables debido a que las buscan como alimento, compañía y ornato (Núñez-García et al. 2012, 17). El concepto de mascota difiere en ambas comunidades, en RA al igual que en lo reportado para Playón (Yunes-Jiménez, 2015, 47), las aves que se tiene como mascota son las que están enfermas y/o son pequeñas y cuando se recuperan o crecen son liberadas. Mientras que en FC es común que las tengan permanentemente como mascotas, sobre todo los psitácidos que son atrapados cuando son pequeños y/o caen de los nidos en las milpas, así como las palomas. Esto coincide con estudios realizados en comunidades mayas de Campeche que reportan que tanto palomas como loros son muy preciadas como mascotas (Retana-Guiascón et al. 2012, 21). Romero-González (2013, 14) reporta usos similares de las aves como alimento y mascota en primarias rurales de San Cristóbal de las Casas, Chiapas. Un aspecto notorio es que en RA y FC las aves que más les gustan coinciden con las que pueden tener como mascotas.

En lo que respecta a las aves que se utilizan como alimento, en RA reportaron no comer aves silvestres, aunque han visto algunas que se consumen en comunidades cercanas y coinciden con las mencionadas por los niños en FC que mencionaron haber comido loros, palomas, entre otros. En general se presentan coincidencias con las especies reportadas para el estado de Chiapas, siendo las más populares los loros, las chachalacas y las palomas (Naranjo-Piñera 2013, 272, 274, 275). Jiménez-Díaz y colaboradores $(2014,93,95)$ han documentado que los lacandones utilizan 27 especies como alimento, siendo las más consumidas el hocofaisán y la cojolita, mismas que también mencionaron los niños en Playón (Yunes-Jiménez 2015, 49). En Tiltepec, Oaxaca se registra un número muy alto de aves comestibles (alrededor de 196 especies), faisanes, palomas, pericos, tucanes y pájaros carpinteros coinciden con lo mencionado en FC. Aunque en RA y FC mencionaron repetidamente a las aves de corral, estas no se tomaron en cuenta.

La relación de los niños con el territorio y la avifauna en su rutina de juegos y de acompañamiento a la milpa y al campo en ambas comunidades es una práctica común y se traduce 
en esta cercanía y conocimiento hacia las aves y la naturaleza. Aunque conocen características como el canto, conducta, alimentación, etc., llama la atención que al preguntarles sobre lo que saben, no se asumen como portadores de conocimiento y externan su deseo de conocer más al respecto. Es notorio que hay un pensamiento generalizado de que lo único importante y válido es lo que se enseña en la escuela y por lo tanto es lo que deben conocer, lo niños no se sienten como poseedores de un conocimiento significativo o importante.

\section{ANP y CONANP}

En ambas comunidades mostraron un alto interés por la naturaleza, en particular por las aves y todos externaron su inquietud y deseo por aprender más al respecto, esto coincide con los resultados obtenidos por Yunes-Jiménez $(2015,43)$ y Romero-González $(2013,57)$. En este sentido, en las

últimas tres décadas se ha atestiguado un cambio en la actitud general de las personas hacia el entorno natural con un incremento en la toma de conciencia, al entenderse como un componente integral de la naturaleza, lo que ha generado una preocupación social por el estado ambiental y la conservación.

La conservación se basa en tres ejes: la protección, el manejo y la restauración; su implementación en México depende, en gran medida, del monitoreo biológico. Como se mencionaba, en FC existen monitores comunitarios de aves apoyados por la Comisión Nacional para el Conocimiento y Uso de la Biodiversidad (CONABIO) y la CONANP, esto constituye una herramienta para la conservación de la biodiversidad y tanto los niños como los jóvenes y los adultos podrían comenzar a integrar estas prácticas a su conocimiento con miras a conservar y fomentar actividades productivas como el ecoturismo.

Constituye un gran reto integrar estos saberes y conservar la biodiversidad, ya que por lo general hay una incongruencia al tratar de respetar y apoyar a las comunidades que viven en regiones de alta biodiversidad, por ejemplo por un lado cuentan con áreas protegidas comunales, pero por otro se les restringe la caza tradicional. Por lo general se asume que las comunidades no serán capaces de hacer un manejo sustentable, sin embargo existen ejemplos de comunidades que no se rigen por la rentabilidad sino por una administración ambiental colectiva (Alcántara et al. 2015, 2, 12). Otras restricciones asociadas a las ANP son la ganadería extensiva que se ha expresado en la destrucción de hábitat, deforestación y deterioro de la fertilidad de los suelos (Carabias-Lillo et al. 2000, 53). Se sabe que cuando se imponen restricciones sobre el uso de los 
recursos sin promover otras alternativas, se puede crear un rechazo por parte de las poblaciones humanas, en algunos casos provocando un incremento drástico del uso de dichos recursos porque las comunidades tratan de garantizar el beneficio inmediato (Halffter 2011, 183).

Durante el siglo XX la conservación se enfocó en la creación de ANP sin tomar en cuenta que a nivel mundial el $80 \%$ de las 136 ecoregiones terrestres prioritarias se encuentran habitadas por pueblos indígenas. La visión sobre las Reservas es limitada y a largo plazo pudiera ser inoperante ya que en la práctica rara vez se toman en cuenta las condiciones sociales y culturales (Toledo 2005, 67).

El concepto Reserva de la Biosfera considera la incorporación de los pobladores locales, no como elementos aislados y pasivos sino como parte integral que posibilita el acceso y manejo integral y sostenido de los recursos y la conservación del área (Carabias-Lillo et al. 2000, 93). Es la única modalidad que reconoce la presencia humana como parte importante en la estrategia de conservación en nuestro país, sin embargo, existe el riesgo de tomar a la cultura como un asunto político y en un orden cultural-político-económico las prácticas y conocimientos locales se ponen a prueba (Guzmán 2006, 152).

Hay evidencia de que a pesar de la existencia de ANP, una parte importante de la biodiversidad queda fuera de los límites o se desplaza, por lo tanto, debe brindarse especial atención a lo que ocurre en estos límites, en especial a la conservación ligada al uso tradicional de los recursos (Halffter 2011, 180). Las políticas en materia de conservación implican muchas veces que las personas deban acomodar sus saberes a un régimen que puede causar crisis de identidad o etnocidios, entonces no se le debe dar más peso ni a los criterios ecológicos ni a los sociales basados en el desarrollo sustentable (conservacionismo vs. preservacionismo), sino que se debe armar un plan en conjunto (Guzmán 2006, 149, 153).

Las ANP por lo general se mantienen por encima de los intereses de las poblaciones sin que haya una relación con las políticas de desarrollo local y regional, sin embargo la conservación de la biodiversidad es imposible si no se toman en cuenta los factores sociales que la condicionan (Toledo 2005, 77). En las comunidades de estudio se observa la falta de generación y promoción de "políticas culturales", entendidas como la búsqueda del desarrollo sustentable y la biodiversidad inserto en la sociedad, así como a la heterogeneidad social y cultural implicadas (Guzmán 2006, 146). 
La conservación de la biodiversidad en regiones tropicales requiere de nuevas herramientas teóricas, y esto a su vez requiere un cambio de paradigma para la conservación (Toledo 2005, 81) donde el axioma biocultural es básico, no se puede preservar a la biodiversidad sin proteger la diversidad cultural. Para lograrlo se necesita tener enfoques que promuevan soluciones con equipos multidisciplinarios. Ante esta realidad este subcomponente propone desarrollar varias formas de manejo y aprovechamiento sustentable de los recursos naturales de manera persistente, brindando elementos para la diversificación de actividades y detección de usos potenciales, haciendo autodiagnósticos comunitarios y talleres de planeación participativa donde se aborden temas de aprovechamiento y conservación de los recursos naturales (Carabias-Lillo et al. 2000, 81). Aquí es donde la consolidación de la educación intercultural y bilingüe juega un papel importante para hacer frente a los problemas y mejorar las condiciones de vida y de conservación del medio. A partir de ésta se puede lograr integrar a los actores sociales de las comunidades, desde los niños, profesores, madres y padres de familia, cooperativas y monitores comunitarios, ya que recuperando y reconstruyendo las historias y saberes se puede hacer una apropiación de elementos culturales que brinde respuestas para los problemas de sostenibilidad.

Un valor agregado en estas comunidades es que, por lo general, estas culturas asumen una posición de respeto hacia la naturaleza y defensa del ambiente (López 2001, 18), algo básico en una zona tan amenazada como la selva lacandona donde además se encuentra un número importante de aves y otros animales carismáticos, que se encuentran en peligro de extinción o amenazados. Esto se observa desde edades tempranas y así lo demuestran los niños del estudio, que no están de acuerdo en lastimar a estos organismos.

La diverdad de aves constituye un valioso atractivo para el uso recreativo y esto representa una alternativa de uso sustentable, que junto con la apreciación de paisajes pueden diversificar las fuentes de ingresos económicos y lograr una unión entre los intereses de conservación y desarrollo sustentable (Carabias-Lillo et al. 2000, 60).

En especial en FC hay al menos una cooperativa (Siyaj Chan) interesada en trabajar con niños, diseminar el conocimiento adquirido y fomentar acciones sustentables como el ecoturismo. Existe la necesidad de establecer políticas y prácticas normativas para el uso de los recursos naturales que garanticen su conservación a largo plazo y la búsqueda inmediata de alternativas de manejo sustentable para hacerlos compatibles, tanto cultural y económicamente, con los usos y costumbres de las comunidades y el mejoramiento de su calidad de vida, así como ecológicamente 
con los objetivos de la REBIMA (Carabias-Lillo et al. 2000, 82). El ecoturismo es una actividad productiva adecuada para las comunidades del presente estudio, como una solución que enlaza y da soporte a otras actividades productivas (Guzmán 2006, 170). Algo fundamental es que a los visitantes les gustan los paisajes conservados y observar las especies protegidas en ellos (Morales 2006, 260), esto lo tienen claro y lo mencionan constantemente los niños en RA y en menor medida los de FC.

Es importante señalar que el turismo también puede ser un "lugar de encuentro intercultural" en la medida que se unen grupos interesados por ejemplo en la protección de los patrimonios naturales, arqueológicos y culturales, y del paisaje como un motor para difundir tanto los recursos naturales como los culturales (Morales 2006, 254). En países como Chile se ha optado por impulsar un programa de turismo comunitario con una visión que sigue dos líneas, la educativa y la formativa en pro de una sostenibilidad de una conciencia ambiental por medio de la apropiación por parte de las comunidades Atacameña y Quechua que se han involucrado con sus recursos y hace que los identifiquen como un grupo étnico en particular, esto integra el CT y el aspecto cultural en lo que ellos llaman "ecoetnoturismo", que va acompañado con proyectos de gestión ambiental en las escuelas (Morales 2006, 259).

Dicho ecoturismo con enfoque biocultural se ha implementando por los miembros de la cooperativa Siyaj Chan que trabaja en el MNY en FC y que ellos denominan "arqueoturismo”y "ecoarqueología" que ha surgido de la necesidad de conjuntar los conocimientos locales sobre la biodiversidad con la cultura y la historia. Actualmente brindan a los turistas información que abarca ambos aspectos, sin embargo requieren de programas que apoyen el enfoque biocultural, ya que hace falta actualizar la información y mencionan que en la parte de flora y fauna aun se quedan cortos (datos observados en campo). Se puede aprovechar dicho interés para implementar programas en conjunto con instituciones como la CONANP y las escuelas de las localidades, lo que además de reforzar el CT ayudaría a que los niños reconozcan la importancia de sus acciones en la conservación y el trabajo de las ANP, algo que la mayoría desconoce y es primordial debido a los problemas causados por la presencia humana que si no son atendidos pueden ocasionar mayor mortalidad de especies que los eventos estocásticos en las ANP (Woodroffe y Ginsberg 1998, 2128).

En cuanto a RA, que no cuenta con apoyo y es una comunidad que busca y gestiona sus propios recursos, lo adecuado sería que las instituciones la tomaran en cuenta para realizar acciones 
en conjunto con sus niños quienes reconocen que las aves son un importante atractivo turístico. Al promover esto se puede llegar a una comprensión y empoderamiento de las comunidades indígenas hacia las actividades turísticas, rescatando un patrimonio arqueológico y natural. La cultura y las tradiciones, entre otros elementos son constituyentes de la vida cotidiana en las comunidades y si se les da el valor que tienen representan un interés para el visitante y las nuevas generaciones (Morales 2006, 260).

La REBIMA es considerada como el área de mayor biodiversidad de las zonas tropicales en México, su conservación a largo plazo depende de líneas de acción que contemplen a las comunidades. Se debe generar un marco de conocimiento sobre recursos naturales y sus interrelaciones, potenciales y deficiencias a través de un programa de investigación científica en la REBIMA. Los estudios e investigaciones generados deben tomarse en cuenta en las acciones y políticas de manejo (Carabias-Lillo et al. 2000, 82), sin olvidar al monitoreo como parte fundamental del "manejo adaptativo" de los recursos naturales; ya que este brinda la información sobre los cambios poblacionales ocasionados por el propio manejo en las ANP (Villaseñor-Gómez y Santana 2003, 232,233). Por esto se requiere que permanezcan y se amplíen los programas de monitoreo comunitario para fines de conservación.

\section{Conclusiones}

Los niños de RA y FC tienen amplios conocimientos con relación a la naturaleza y a la biodiversidad local, en particular sobre las aves, y muestran un alto aprecio por ellas. Sin embargo, este conocimiento se encuentra en riesgo debido a factores como la pérdida de la lengua y a cambios generacionales y tecnológicos que traen consigo cambios cognitivos, informáticos y culturales que junto con los procesos actuales de la educación formal pueden provocar un desarraigo cultural y pérdida de memoria biocultural (Toledo y Barrera-Bassols 2008, 16; Núñez-García et al. 2012, 1, 28). No existen estudios etnobiológicos suficientes para demostrar la pérdida y erosión de dichos conocimientos, y esto debe tomarse en cuenta en el futuro inmediato si se quiere preservar e integrar los saberes locales en la toma de decisiones en materia de conservación, más urgentemente en comunidades de gran importancia que se encuentran en zonas de influencia de ANP.

El conocimiento local de los niños sobre las aves es adquirido mayormente en su casa a través de sus padres y madres, así como de sus hermanos mayores; también en su dinámica de 
juegos cotidianos donde pueden observar a las aves de manera constante. En los hijos varones además cuando acompañan a sus padres en las labores de la milpa o el campo.

La comunidad de RA muestra particular reconocimiento sobre la importancia de la conservación y el cuidado de los recursos naturales, y esto permea hacia los niños; sin embargo, cuando se trata de proteger a las aves los menores se enfocan a acciones directas antrópicas como no matarlas. En cambio, en FC los niños tienen muy claro que existe una relación entre la perturbación y la contaminación del medio con la supervivencia de las aves, y proponen acciones de conservación tanto directas antrópicas como indirectas más relacionadas con el cuidado de la selva. La transmisión de conocimientos, usos y prácticas locales así como la valoración y percepción, deben ser consideradas en políticas públicas de educación y conservación de los recursos naturales.

Es deseable que la actividad científica tome en cuenta los problemas de las comunidades y busque alternativas de desarrollo sustentable proyectando sus resultados a nivel regional para implementar programas de desarrollo estatal y regional (Halffter 2011, 182). El reconocimiento y valoración de los saberes desde el espacio académico puede ser un instrumento intercultural para el desarrollo y preservación de los mismos (Aldasoro y Maya 2010, 149; Núñez- García 2012, 17), en vías de una mayor justicia cognitiva (de Sousa 2009, 12).

Tomar en cuenta el conocimiento que los niños poseen, debe tener un papel fundamental en la orientación de procesos futuros de sustentabilidad y conservación. Se requieren medidas que integren de forma transdisciplinaria los saberes locales, percepciones y conocimiento técnico para facilitar la realización de acciones y talleres conjuntos con instituciones gubernamentales y asociaciones civiles con miras a la conservación y manejo sustentable de los recursos. Un punto a favor que puede integrar paulatinamente a los niños en estas actividades es la presencia actual de monitores comunitarios en la zona y/o de guías comunitarios.

\section{Referencias}

Alcántara, Graciela. (2003). Las Aves según la percepción en importancia actual para los zapotecos de San Miguel Tiltepec (Distrito de Ixtlán), Oaxaca: Un estudio etnozoológico. Tesis de Maestría en Ciencias (Biología Animal), Universidad Nacional Autónoma de México.

Alcántara-Salinas, Graciela, Eugene Hunn y Jaime E. Rivera-Hernández. (2015). Avian Biodiversity in Two Zapotec Communities in Oaxaca: The Role of Community-Based 
Conservation in San Miguel Tiltepec and San Juan Mixtepec, Mexico. Human Ecology, 43(5): 735-748.

Aldasoro, E. Miriam y Blanca Rosa Maya. (2010). La Conservación in situ del conocimiento ambiental Pjiekakajoo (tlahuica) a través de actividades técnico-pedagógicas. En Sistemas biocognitivos tradicionales: paradigmas en la conservación biológica y el fortalecimiento cultural, compilado por Ángel Moreno, María Teresa Pulido, Ramón Mariaca, Raúl Valadez, Paulina Mejía y Tania V. Gutiérrez, 147-152. México: Asociación Etnobiológica Mexicana A. C., Global Diversity Foundation, El Colegio de la Frontera Sur, Universidad Autónoma del Estado de Hidalgo, Sociedad Latinoamericana de Etnobiología.

Aldasoro Maya, E. Miriam. (2012). Documenting and contextualizing Pjiekakjoo (Tlahuica) knowledges though a collaborative research project. Tesis de doctorado en Filosofía, Universidad de Washington.

Benites, Maristela y Simone B. Mamede. (2008). Mamíferos e aves como instrumentos de educação e conservação ambiental em corredores de biodiversidade do cerrado, Brasil. Mastozoología Neotropical 15(2): 261-271.

Berkes, Fikret. (1999). Sacred ecology. Filadelfia: Taylor \& Francis.

Boege, Eckart. (2008). El patrimonio biocultural de los pueblos indígenas de México: hacia la conservación in situ de la biodiversidad y agrodiversidad en los territorios indígenas. México: Instituto Nacional de Antropología e Historia y Comisión Nacional para el Desarrollo de los Pueblos Indígenas.

Bonta, Mark. (2010). Ethnoornithology and biological conservation. En Ethno-ornithology, birds, Indigenous Peoples, Culture and Society, compilado por Sonia Tidemann y Andrew Gossler, 13-29. Londres: Earthscan.

Cano Ingreet, Juliet. (2013). De montaña a reserva forestal: Colonización, sentido de comunidad y producción de la conservación ecológica en el sureste de la Selva Lacandona, México. Tesis de Doctorado en Ciencias Sociales, Centro de Investigaciones y Estudios Superiores en Antropología Social CIESAS, Guadalajara.

Carabias, Julia, Paula Meli, Gilberto Hernández y Gabriela Almeida. (2006). Estrategia de restauración ambiental y prevención de incendios en ejidos ribereños del río Lacantún, colindantes a la Reserva de la Biosfera Montes Azules. Informe Técnico. México: UNAMINE http://www.inecc.gob.mx/descargas/cclimatico/e2006l.pdf (29 de mayo de 2017)

№ 19, Vol. 9 (2), 2017. ISSN 2007 - 0705, pp.: 660 - 716 
Carabias-Lillo, Julia, Enrique Provencio, Javier de la Maza, David Gutiérrez, Mario Gómez y Alejandro López. (2000). Programa de manejo Reserva de la Biosfera Montes Azules. México, D.F: Instituto Nacional de Ecología. http://www.conanp.gob.mx/datos_abiertos/DGCD/56.pdf (29 de mayo de 2017).

Guzmán Chávez, Mauricio Genet. (2006). Biodiversidad y conocimiento local: del discurso a la práctica basada en el territorio. Espiral Guadalajara 13(37): 145-176.

CEIEG. (2010). Secretaría de Planeacion Gestión pública y Programa de gobierno del estado de Chiapas.http://www.ceieg.chiapas.gob.mx/home/wpcontent/uploads/downloads/InfoPlanMunicipal/Capitulo_1.1_POBLACION_Y_LOCALI DADES.pdf (29 de mayo de 2017).

CONABIO. (2013). La biodiversidad en Chiapas: Estudio de Estado. México: Comisión Nacional para el Conocimiento y Uso de la Biodiversidad Gobierno del Estado de Chiapas.

Cristancho, Sergio y Joanne Vining. (2009). Perceived Intergenerational Differences in the Transmission of Traditional Ecological Knowledge (TEK) in Two Indigenous Groups from Colombia and Guatemala. Culture y Psychology 15(2): 229-254.

De Sousa, Boaventura. (2009). Una Epistemología del Sur, México: Siglo XXI Editores.

Dufour, Darna. (2006). Biocultural approaches in human biology. American Journal of Human Biology 18(1): 1-9.

Dunn, Jon y Jonathan Alderfer. (1999). National Geographic field guide to the birds of North America. National Geographic Society US.

Durand, Leticia y Fernanda Figueroa. (2012). Interfases de conocimiento, ecoturismo y conservación en la Selva Lacandona. El caso de la subcomunidad de Frontera Corozal. Ponencia preparada para el III Congreso Nacional de Ciencias Sociales, COMECSO, Ciudad de México.

Durand, Leticia y Fernanda Figueroa. (2014). Sobrevivir en una selva de proyectos. Relatos sobre la conservación en la comunidad Nueva Palestina en la Reserva de la Biosfera Montes Azules, Chiapas. En Paradojas de las tierras prometidas en Chiapas, compilado por Legorreta Carmen, Conrado Márquez y Tim Trench, 107-127. México, D.F.: Universidad Nacional Autónoma de México. 
Fernández, Rosalía, Luciana Porter-Bolland y Jaume SUREDA, J. (2010). Percepciones y conocimientos ambientales de la población infantil y juvenil de una comunidad rural de Veracruz, México. Revista de Educación y Desarrollo 12: 25-44.

Gobierno del estado de Chiapas, Secretaría de Desarrollo Social. (2006). Informe final de actividades, experiencia exitosa de conservación y aprovechamiento sustentable en el N.C.P.E. Reforma Agraria. Proyecto Desarrollo Social Integrado y Sostenible. Chiapas. Tuxtla Gutiérrez, Chiapas: México-Unión Europea. http://www.biblioteca.unach.mx/images/2011/prodesis/planeacion/produccion\%20de\%20 materiales\%20de\%20capacitacion\%20y\%20divulgacion\%20cientifica.pdf (29 de mayo de 2017).

Guber, Rosana. (2001) La etnografía: método, campo y reflexividad. Colombia: Grupo Editorial Norma.

Guerrero-Martínez, Fernando y Rafael Serrano-González. (2012). Aves medicinales y agoreras en tres grupos mayenses de Chiapas. En Aves y Huertos de México, compilado por Marco A. Vásquez-Dávila y Diana Lope-Alzina, 30-32. Oaxaca, México: Carteles editores, CONACYT e Instituto Tecnológico del Valle de Oaxaca.

Guirao-Cruz, Rafael Eslein, Lilly Gama y Stefan Louis Arriaga-Weiss. (2012). El quetzal (Pharomachrus mocinno) en el municipio zoque de Tapalapa, Chiapas. En Aves y Huertos de México, compilado por Marco A. Vásquez-Dávila y Diana Lope-Alzina, 32-33. Oaxaca, México: Carteles editores, CONACYT e Instituto Tecnológico del Valle de Oaxaca.

Halffter, Gonzalo. (2011). Reservas de la Biosfera: problemas y oportunidades en México. Acta zoológica mexicana 27(1): 177-189.

Howell, Steve y Sophie Webb. (1995). A guide to the birds of Mexico and northern Central America. Oxford University Press.

Hull, Kerry y Rob Fergus. (2011). Ethno-ornithological perspectives on the Ch'ol Maya. Reitaku Review 17: 42-92.

Hunn, Eugene S. (2002). Evidence for the precocious acquisition of plant knowledge by Zapotec children. En Ethnobiology and Biocultural Diversity: Proceedings, compilado por John R. Stepp, Felice S. Wyndham y Rebecca K. Zarger, 604-613. Georgia: McNaughton \& Gunn. INEGI. (2010). Principales resultados del Censo de Población y vivienda. Chiapas, México. http://www3.inegi.org.mx/sistemas/SCITEL/default?ev=5 (29 de mayo de 2017). 
Jiménez-Díaz, Juan Elmar, Marco Antonio Vásquez-Dávila, Eduardo Jorge Naranjo Piñera y Martha Patricia Jerez-Salas. (2014). Las relaciones humano-aves en Lacanjá-Chansayab, selva Lacandona, Chiapas, México. En Aves, personas y culturas. Estudios de Etnoornitología, compilado por Vásquez-Dávila Marco Antonio, 1:83-106. Oaxaca, México: COMACYT ITVO Carteles Editores UTCH.

Kauffman, Kenn. (2005). Guía de campo a las aves de Norteamérica. Nueva York: Houghton Mifflin Company.

Legorreta, Carmen. (2014). Introducción. En Paradojas de las tierras prometidas en Chiapas, compilado por Legorreta Carmen, Conrado Márquez y Tim Trench, 11-19. México, D.F.: Universidad Nacional Autónoma de México.

López, Luis Enrique. (2001). La cuestión de la interculturalidad y la educación latinoamericana. Documento de trabajo presentado al Seminario sobre prospectivas de la educación en la región de América Latina y el Caribe, 382-406. Santiago de Chile. http://red.pucp.edu.pe/ridei/files/2011/08/731.pdf (29 de mayo de 2017).

MacKinnon, Barbara. (2004). Manual para el desarrollo y capacitación de guías de aves. Quintana Roo, México: Amigos de Sian Káan, A.C.

Maffi, Luisa. (2005). Linguistic, cultural, and biological diversity. Annual Review of Anthropology 34: 599-617.

Morales, Héctor Freddy. (2006). Turismo comunitario: una nueva alternativa de desarrollo indígena. Revista de Antropología Iberoamericana edición electrónica. Marzo-Julio 1(2): 249-264 http://www.redalyc.org/articulo.oa?id=62310205 (29 de mayo de 2017).

Naranjo-Piñera, Eduardo. (2013). Uso de la fauna silvestre. En La biodiversidad en Chiapas: Estudio de Estado, compilado por CONABIO, 271-280. México: CONABIO, Gobierno del estado de Chiapas.

Navarro-Sigüenza, Adolfo G., Ma. Fanny Rebón-Gallardo, Alejandro Gordillo-Martínez, A. Townsend Peterson, Humberto Berlanga-García y Luis Antonio Sánchez-González. (2014). Biodiversidad de aves en México. Revista Mexicana de Biodiversidad 85: 476-495.

Nemogá, Gabriel. (2016). Diversidad Biocultural: Innovando en investigación para la conservación. Acta Biológica Colombiana 21(1) Supl 311-319.

Núñez-García, Rosa María, Mario E. Fuente-Carrasco y Marco Antonio Camacho. (2012). El saber etno-ornitológico como patrimonio biocultural de Ixtlán de Juárez. En Conocimiento 
indígena contemporáneo y patrimonio biocultural en la Sierra Juárez de Oaxaca Aportaciones empíricas y analíticas hacia la sustentabilidad, compilado por Fuente Mario Enrique, Faustino Ruiz y Ciro Aquino, 15-33. Ixtlán de Juárez Oaxaca, México: Universidad de la Sierra de Juárez.

Oviedo Gonzalo, Flavia Noejovich y Teodora Zamudio. (2007). Desafíos para el mantenimiento de los conocimientos tradicionales en América Latina. Resumen Ejecutivo del Informe solicitado por la Conferencia de las Partes del Convenio sobre Diversidad Biológica. https://cmsdata.iucn.org/downloads/tk_in_la_resumen_ejecutivo_marzo_07_1.pdf (29 de mayo de 2017).

Pérez-Gil, Ramón, Fernando Jaramillo, Ana María Muñiz y Marta Gabriela Torres. (1995). Importancia económica de los vertebrados silvestres de México. CONABIO, México, D.F.

Plan de desarrollo municipal Marqués de Comillas. (2011-2012). Chiapas, México: Ayuntamiento Municipal Constitucional. http://www.maderasdelpueblo.org.mx/archivos/pdf/planmarques.pdf (29 de mayo de 2017).

Retana-Guiascón, Oscar Gustavo, Román Abraham Puc-Gil y Lucía Guadalupe Martínez-Pech. (2012). Uso de la fauna silvestre por comunidades mayas de Campeche. El caso de las aves. En Aves y Huertos de México, compilado por Marco A. Vásquez-Dávila y Diana G. LópeAlzina, 20-21. México: Carteles editores, CONACYT- Instituto Tecnológico del Valle de Oaxaca.

RAE, Real Academia Española (2017). http://www.rae.es/consultas/los-ciudadanos-y-lasciudadanas-los-ninos-y-las-ninas (5 de septiembre de 2017).

Ramírez, Jorge E. (2006). Variación en la composición de comunidades de aves en la Reserva de la Biosfera Montes Azules y áreas adyacentes, Chiapas, México. Biota Neotropica 6(2): 119.

Rivero-Romero, Alexis D., Ana I. Moreno-Calles, Alejandro Casas, Alicia Castillo y Andrés Camou-Guerrero. (2016). Traditional climate knowledge: a case study in a peasant community of Tlaxcala, Mexico. Journal of Ethnobiology and Ethnomedicine 12(1): 33.

Romero-González, María Primavera. (2013). Percepciones de niñas y niños sobre las aves en primarias rurales y urbanas en San Cristóbal de Las Casas, Chiapas. Tesis de Maestría en 
Ciencias en Recursos Naturales y Desarrollo Rural. El Colegio de la Frontera Sur. San Cristóbal de Las Casas, Chiapas, México.

Sarukhán, José, Patricio Koleff, Julia Carabias, Jorge Soberón, Rodolfo Dirzo, Jorge LlorenteBousquets, Gonzalo Halffter, Renée González, Ignacio March, Alejandro Mohar, Salvador Anta y Javier de la Maza. (2009). Capital natural de México, Síntesis: Conocimiento actual, evaluación y perspectivas de sustentabilidad. CONABIO, México. http://www.biodiversidad.gob.mx/pais/pdf/CapNatMex/Capital\%20Natural\%20de\%20Me xico_Sintesis.pdf (29 de mayo de 2017).

Schmelkes, Sylvia. (2006). La interculturalidad en la educación básica. Revista Prelac 3: 120-127.

Tejeda, Carlos y Conrado Márquez. (2006). Apropiación territorial y aprovechamiento de recursos forestales en la comunidad Frontera Corozal, Selva Lacandona, Chiapas, México. Revista de Geografía Agrícola, julio-diciembre: 79-95.

Tidemann, Sonia, Sharon Chirgwin y J. Ross Sinclair. (2010). Indigenous Knowledges, Birds that Have Spoken and Science. En Ethno-ornithology, birds, Indigenous Peoples, Culture and Society, compilado por Sonia Tidemann y Andrew Gossler, 3-12. Londres: Earthscan.

Toledo, Victor M. (2005). Repensar la conservación: ¿áreas naturales protegidas o estrategia bioregional? Gaceta ecológica 77: 67-83.

Toledo, Victor M. y Narciso Barrera-Bassols. (2008). La memoria biocultural, la importancia ecológica de las sabidurías tradicionales. Barcelona España: Icaria editorial.

Toledo, Victor M. (2003). Ecología, espiritualidad y conocimiento: De la Sociedad del Riesgo a la Sociedad Sustentable. México: Universidad Iberoamericana, Programa de las Naciones Unidas para el Medio Ambiente Oficina Regional para América Latina y el Caribe PNUMA, Grupo Editorial Formato.

UNESCO. (2002). Declaración Universal sobre la Diversidad Cultural, una visión una plataforma conceptual un semillero de ideas un paradigma nuevo. Serie sobre la Diversidad Cultural $\mathrm{N}^{\circ}$ 1. Perú. 66pp. http://unesdoc.unesco.org/images/0012/001271/127162s.pdf (29 de mayo de 2017).

Van Perlo, Ber. (2006). Birds of Mexico and Central America. Princeton ilustrated Checklist.

Venegas-Segura, Andrés Antonio. (2013). Ideas de naturaleza: configuración desde diferentes perspectivas culturales e implicaciones educativas. Magis. Revista Internacional de 
Investigación en Educación, especial Enseñanza de las ciencias y diversidad cultural. Pontificia Universidad Javeriana Bogotá, Colombia 6(12): 169-183.

Villaseñor-Gómez, Laura y Patricia Manzano. (2003). La educación ambiental y las aves: experiencias en México. En Conservación de aves. Experiencias en México, compilado por Héctor Gómez y Adán Oliveras. 379-409. México, D.F: CIPAMEX, National Fish and Wildlife Foundation, CONABIO.

Villaseñor-Gómez, José Fernando y Eduardo Santana. (2003). El monitoreo de poblaciones: herramienta necesaria para la conservación de aves en México. En Conservación de aves. Experiencias en México, compilado por Héctor Gómez y Adán Oliveras. 224-409. México, D.F: CIPAMEX, National Fish and Wildlife Foundation, CONABIO.

Woodroffe, Rosie y Joshua R. Ginsberg. (1998). Edge effects and the extinction of populations inside protected areas. Science, 280(5372): 2126-2128.

Yunes-Jiménez, Laila. (2015). La niñez y las aves de Playón de La Gloria y Tziscao, Chiapas: Una aproximación didáctica a su uso y conocimiento. Tesis de Maestría en Ciencias en Recursos Naturales y Desarrollo Rural. El Colegio de la Frontera Sur. San Cristóbal de Las Casas, Chiapas, México.

Zent, Stanford. (2001). Acculturation and ethnobotanical knowledge loss among the Piaroa of Venezuela: Demonstration of a quantitative method for the empirical study of traditional ecological knowledge change. En On biocultural diversity: Linking language, knowledge, and the environment, compilado por Luisa Maffi, 190-211. Washington: Smithsonian Institution Press.

\section{Anexo 1.}

Listado obtenido en Frontera Corozal el 17 de octubre de 2016 en un recorrido de monitoreo y vigilancia comunitaria con Siyaj chan, con desplazamiento de $1.6 \mathrm{~km}$ por un transecto de la zona arqueológica de Yaxchilán, en un horario de 7:45 am a 9:50 am.

\begin{tabular}{llllll}
\hline & Nombre común & $\begin{array}{l}\text { Observa- } \\
\text { dos }\end{array}$ & Nombre científico & NOM-059 & UICN \\
\hline 1 & Gavilán Bidentado & 1 & Harpagus bidentatus & Pr & LC \\
2 & Aguililla Caminera & 1 & Rupornis magnirostris & & LC \\
3 & Aguililla Alas Anchas & 3 & Buteo platypterus & Pr & LC \\
4 & Colibrí Cándido & 1 & Amazilia candida & & LC \\
\hline
\end{tabular}

No 19, Vol. 9 (2), 2017. ISSN 2007 - 0705, pp.: 660 - 716 
Conocimiento y percepción de la avifauna en niños de dos comunidades en la selva Lacandona, Chiapas, México: hacia una conservación biocultural

\begin{tabular}{|c|c|c|c|c|c|}
\hline 5 & Coa Violácea Norteña & 2 & Trogon caligatus & & $\mathrm{LC}$ \\
\hline 6 & Martín Pescador de Collar & 4 & Megaceryle torquata & & $\mathrm{LC}$ \\
\hline 7 & Jacamar Cola Canela & 1 & Galbula ruficauda & A & $\mathrm{LC}$ \\
\hline 8 & Tucán Pico Canoa & 3 & Ramphastos sulfuratus & A & LC \\
\hline 9 & Loro Corona Blanca & 9 & Pionus senilis & A & $\mathrm{LC}$ \\
\hline 10 & Perico Pecho Sucio & 4 & Eupsittula nana & $\operatorname{Pr}$ & $\mathrm{LC}$ \\
\hline 11 & Trepatroncos Bigotudo & 1 & $\begin{array}{l}\text { Xiphorhynchus } \\
\text { flavigaster }\end{array}$ & & $\mathrm{LC}$ \\
\hline 12 & Papamoscas Vientre Amarillo & 1 & Empidonax flaviventris & & $\mathrm{LC}$ \\
\hline 13 & Papamoscas Triste & 2 & Myiarchus tuberculifer & & $\mathrm{LC}$ \\
\hline 14 & Maullador Gris & 1 & Dumetella carolinensis & & $\mathrm{LC}$ \\
\hline 15 & Chipe Charquero & 2 & Parkesia noveboracensis & & $\mathrm{LC}$ \\
\hline 16 & Pavito Migratorio & 1 & Setophaga ruticilla & & $\mathrm{LC}$ \\
\hline 17 & Chipe Dorso Verde & 1 & Setophaga virens & & $\mathrm{LC}$ \\
\hline 18 & Tangara Alas Amarillas & 1 & Thraupis abbas & & $\mathrm{LC}$ \\
\hline 19 & Eufonia Garganta Amarilla & 2 & Euphonia hirundinacea & & $\mathrm{LC}$ \\
\hline 20 & Eufonia Olivácea & 2 & Euphonia gouldi & $\operatorname{Pr}$ & $\mathrm{LC}$ \\
\hline
\end{tabular}

Listado obtenido en Frontera Corozal 17 de octubre de 2016 en un recorrido de monitoreo y vigilancia comunitaria con Siyaj chan, con desplazamiento de $1.6 \mathrm{~km}$ por un transecto de la zona arqueológica de Yaxchilán y sendero de la garganta, en un horario de 7:26 am a 9:25 am.

\begin{tabular}{|c|c|c|c|c|c|}
\hline & Nombre común & $\begin{array}{l}\text { Observa- } \\
\text { dos }\end{array}$ & Nombre científico & $\begin{array}{l}\text { NOM- } \\
059\end{array}$ & $\begin{array}{l}\text { UIC } \\
\mathbf{N}\end{array}$ \\
\hline 1 & Hocofaisán & 3 & Crax rubra & $\mathrm{A}$ & $\mathrm{VU}$ \\
\hline 2 & Paloma Triste & 2 & Patagioenas nigrirostris & $\operatorname{Pr}$ & $\mathrm{LC}$ \\
\hline 3 & Paloma Cabeza Gris & 1 & Leptotila plumbeiceps & & $\mathrm{LC}$ \\
\hline 4 & Cuclillo Canelo & 1 & Piaya cayana & & $\mathrm{LC}$ \\
\hline 5 & Jacamar Cola Canela & 1 & Galbula ruficauda & A & $\mathrm{LC}$ \\
\hline 6 & Tucancillo Collarejo & 1 & Pteroglossus torquatus & $\operatorname{Pr}$ & $\mathrm{LC}$ \\
\hline 7 & Tucán Pico Canoa & 3 & Ramphastos sulfuratus & $\mathrm{A}$ & $\mathrm{LC}$ \\
\hline 8 & Carpintero Cheje & 1 & Melanerpes aurifrons & & $\mathrm{LC}$ \\
\hline 9 & Carpintero Pico Plateado & 2 & Campephilus guatemalensis & $\operatorname{Pr}$ & $\mathrm{LC}$ \\
\hline 10 & Hormiguero Cholino Cara Negra & 2 & Formicarius analis & & $\mathrm{LC}$ \\
\hline 11 & Trepatroncos Cabeza Gris & 1 & Sittasomus griseicapillus & & $\mathrm{LC}$ \\
\hline 12 & Trepatroncos Canelo & 1 & Dendrocincla homochroa & & $\mathrm{LC}$ \\
\hline 13 & Trepatroncos Sepia & 1 & Dendrocincla anabatina & $\operatorname{Pr}$ & $\mathrm{LC}$ \\
\hline 14 & Papamoscas Tropical & 1 & Contopus cinereus & & $\mathrm{LC}$ \\
\hline 15 & Luis Pico Grueso & 2 & Megarynchus pitangua & & $\mathrm{LC}$ \\
\hline 16 & Saltarín Cabeza Roja & 1 & Ceratopipra mentalis & & $\mathrm{LC}$ \\
\hline 17 & Saltarín café & 1 & Schiffornis veraepacis & & $\mathrm{LC}$ \\
\hline 18 & Chara Pea & 21 & Psilorhinus morio & & $\mathrm{LC}$ \\
\hline 19 & Saltapared Pecho Blanco & 1 & Henicorhina leucosticta & & $\mathrm{LC}$ \\
\hline 20 & Maullador Gris & 1 & Dumetella carolinensis & & $\mathrm{LC}$ \\
\hline 21 & Saltador Cabeza Negra & 4 & Saltator atriceps & & $\mathrm{LC}$ \\
\hline 22 & Piranga Hormiguera Garganta Roja & 1 & Habia fuscicauda & & $\mathrm{LC}$ \\
\hline 23 & Picogordo Cara Negra & 4 & Caryothraustes poliogaster & & $\mathrm{LC}$ \\
\hline 24 & Oropéndola de Moctezuma o Zacua & 1 & Psarocolius montezuma & $\operatorname{Pr}$ & $\mathrm{LC}$ \\
\hline
\end{tabular}

No 19, Vol. 9 (2), 2017. ISSN 2007 - 0705, pp.: 660 - 716 


\section{Anexo 2.}

Algunos aspectos por los que los niños de LV reconocen a las aves.

\begin{tabular}{|c|c|c|}
\hline Ave & Como lo reconocen & Escuela \\
\hline águila & tamaño y sonido, color café y blanco, o gris y café, uñas grandes y largas & LV \\
\hline búho & vuelo, canto y ojos amarillos, color café y negro y patas oscuras & LV \\
\hline carpintero & cabeza roja, negro y blanco, porque se escucha cuando pega en troncos & LV \\
\hline *chachalaca & color café y grito & LV \\
\hline chipe & canto & LV \\
\hline cojolita & color & LV \\
\hline colibrí & es pequeño, vuela rápido, color de alas y pico largo & LV \\
\hline faisán & color rojo, tamaño grande y tiene plumas en la cabeza & LV \\
\hline garza & color blanco, tamaño grande, cuello y pico largos y patas largas, sonido & LV \\
\hline gavilán & plumas y por el tamaño & LV \\
\hline guacamaya & color rojo, azul y amarillo & LV \\
\hline *loro & tamaño y color verde-amarillo, cabeza roja o amarilla, pico amarillo y azul y su voz & LV \\
\hline martín pescador & colores blanco y negro & LV \\
\hline *paloma & por sus tres colores, tiene azul y café, o negro y blanco con patas rojas & LV \\
\hline pato de monte & color café, tipo de pico y patas & LV \\
\hline pea & color amarillo y sonido & LV \\
\hline *perdiz & color café y tamaño & LV \\
\hline *perico & tamaño y color & LV \\
\hline pijiji & color amarillo y café & $\mathrm{LV}$ \\
\hline quetzal & por su tamaño, color verde y rojo, cola larga y verde de $39 \mathrm{~cm}$ & LV \\
\hline tapacamino & color y canto & LV \\
\hline tortolita & color café, está pequeña y por su canto & LV \\
\hline tucán & tamaño, por el pico largo, por el color del pecho, colores amarillo rojo y negro & LV \\
\hline zanate & color negro y por su pico & LV \\
\hline zopilote & color negro, cabeza pelada y color del cuello, pico grande y su grito & LV \\
\hline zopilote rey & tamaño más grande, color blanco y cuello rojo, & LV \\
\hline zorzal & colores gris y café & LV \\
\hline águila & su grito, tamaño, alas color gris con blanco y negro & JTB \\
\hline búho & café con blanco & JTB \\
\hline carpintero & color rojo y negro, pico largo y sonido que hace cuando pica el palo, tamaño mediano & JTB \\
\hline chachalaca & café con cola larga también tiene negro y gris, tamaño grande a mediano & JTB \\
\hline chipe & tamaño pequeño, su canto, colores café, negro, amarillo, azul y gris & JTB \\
\hline colibrí & $\begin{array}{l}\text { tamaño pequeño, color verde, amarillo y negro, otros tienen café, verde y gris y todos tienen un } \\
\text { pico largo }\end{array}$ & JTB \\
\hline faisan & tamaño grande, de color negro gris y rojo, pico, tamaño, cresta, tiene también color amarillo & JTB \\
\hline garza & su altura, tamaño grande y color blanco, espalda gris, cuello largo blanco-crema & JTB \\
\hline gavilan & gris con un poco de negro y blanco y por su tamaño & JTB \\
\hline golondrina & negro con verde & JTB \\
\hline guacamaya & canto, tamaño grande, forma de su pico, color de cuerpo rojo, amarillo, azul y verde & JTB \\
\hline loro y perico & el tamaño, el color verde, amarillo, azul en la cabeza, pico, el sonido y cuando habla & JTB \\
\hline *paloma & $\begin{array}{l}\text { por su canto, panza blanca, café arriba y negro en la espalda, algunas tienen gris con azul y café, } \\
\text { tamaño mediano }\end{array}$ & JTB \\
\hline pato de agua & café, negro con blanco, gris & JTB \\
\hline perdiz & grande café, negro, rojo y gris & JTB \\
\hline quetzal & color verde y roja y cola verde y larga & JTB \\
\hline tecolote & negro, blanco y gris & JTB \\
\hline *tortolita & $\begin{array}{l}\text { café, azul en la cabeza y alas grises, pueden tener pluma color café, rojo, negro, de tamaño } \\
\text { mediano y por su canto }\end{array}$ & JTB \\
\hline tucán & pico amarillo y grande, colores amarillo, verde, rojo y negro & JTB \\
\hline tucancillo & colores verde y negro y pico largo & JTB \\
\hline zanate & por su sonido, color negro azulado y su tamaño & JTB \\
\hline zopilote & tamaño grande, negro con blanco en la panza, cuello de color rojo y café, su grito & JTB \\
\hline
\end{tabular}

№ 19, Vol. 9 (2), 2017. ISSN 2007 - 0705, pp.: 660 - 716 